\title{
Heterogeneous Double Metal Cyanide Catalyzed Synthesis of Poly( $\varepsilon$-caprolactone) Polyols for the Preparation of Thermoplastic Elastomers
}

\author{
Chinh-Hoang Tran ${ }^{1}{ }^{\mathbb{D}}$, Min-Woong Lee ${ }^{1}$, Sang-Woo Park ${ }^{1}$, Jae-Eon Jeong ${ }^{1}$, Soo-Jeong Lee ${ }^{1}$, Wenliang Song ${ }^{2}$, \\ PilHo Huh ${ }^{1, *(D)}$ and Il Kim ${ }^{1, *(D)}$
}

1 Department of Polymer Science and Engineering, Pusan National University, Busandaehag-ro 63-2, Geumjeong-gu, Busan 46241, Korea; chinhtran@pusan.ac.kr (C.-H.T.); miinwoong93@pusan.ac.kr (M.-W.L.); sangwoo93@pusan.ac.kr (S.-W.P.); jeongjaeeon@pusan.ac.kr (J.-E.J.); sjlee314@pusan.ac.kr (S.-J.L.)

2 School of Materials Science \& Engineering, University of Shanghai for Science and Technology, Shanghai 200093, China; wenliang@usst.edu.cn

* Correspondence: pilho.huh@pusan.ac.kr (P.H.); ilkim@pusan.ac.kr (I.K.)

check for updates

Citation: Tran, C.-H.; Lee, M.-W.; Park, S.-W.; Jeong, J.-E.; Lee, S.-J.; Song, W.; Huh, P.; Kim, I. Heterogeneous Double Metal Cyanide Catalyzed Synthesis of Poly( $\varepsilon$-caprolactone) Polyols for the Preparation of Thermoplastic Elastomers. Catalysts 2021, 11, 1033. https://doi.org/10.3390/catal11091033

Academic Editor: Jacques

Charles Védrine

Received: 29 July 2021

Accepted: 25 August 2021

Published: 26 August 2021

Publisher's Note: MDPI stays neutral with regard to jurisdictional claims in published maps and institutional affiliations.

Copyright: (c) 2021 by the authors. Licensee MDPI, Basel, Switzerland. This article is an open access article distributed under the terms and conditions of the Creative Commons Attribution (CC BY) license (https:// creativecommons.org/licenses/by/ $4.0 /)$.

\begin{abstract}
A series of polycaprolactones (PCLs) with molecular weights of 950-10,100 $\mathrm{g} \mathrm{mol}^{-1}$ and $Ð$ of 1.10-1.87 have been synthesized via one-pot, solvent-free ring-opening polymerization (ROP) of $\varepsilon$-caprolactone (CL) using a heterogeneous double metal cyanide (DMC) catalyst. Various initiators, such as polypropylene glycol, ethylene glycol, propylene glycol, glycerol, and sorbitol, are employed to tune the number of hydroxyl end groups and properties of the resultant PCLs. Kinetic studies indicate that the DMC-catalyzed ROP of CL proceeds via a similar mechanism with the coordination polymerization. Branched PCLs copolymers are also synthesized via the DMC-catalyzed copolymerization of CL with glycidol. The $\alpha, \omega$-hydroxyl functionalized PCLs were successfully used as telechelic polymers to produce thermoplastic poly(ester-ester) and poly(esterurethane) elastomers with well-balanced stress and strain properties.
\end{abstract}

Keywords: double metal cyanide; heterogeneous catalysis; caprolactone; ring-opening polymerization; thermoplastic elastomer

\section{Introduction}

Thermoplastic elastomers (TPEs) have attracted great interest for both biomedical and industrial applications because of their unique mechanical properties compared with traditional rubbers [1-3]. Thermoplastic poly(ether-ester) (TPEE) and polyurethane (TPU) elastomers are the representative commercial TPEs bearing amorphous soft segment and crystalline hard segment domains. Conventional TPEEs and TPUs have used polytetramethylene ether glycol (PTMEG) as soft segments.

Alternatively, polyester-based TPEs have gained increasing attention due to their biocompatibility and biodegradability [4,5]. $\alpha, \omega$-Hydroxyl terminated telechelic polyesters

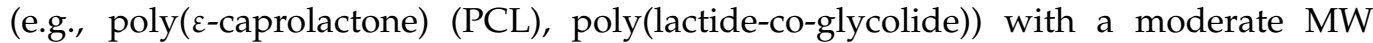
(3000-6000 $\mathrm{g} \mathrm{mol}^{-1}$ ) are effective precursors for the synthesis of hydrolytically degradable TPU elastomers [6-8]. On the other hand, polyesters with a narrow polydispersity would be useful for biomedical and pharmaceutical applications, e.g., as biodegradable implant materials and drug delivery systems $[9,10]$. In addition to aliphatic polyesters, polyesters with complex macromolecular architectures, especially star and branched polyesters, are also attractive candidates for viscosity modifiers and plasticizers [11,12].

Polyesters are typically synthesized via two main pathways: (i) polycondensation of aliphatic dicarboxylic acids and (ii) ring-opening polymerization (ROP) of cyclic carboxylic esters $[13,14]$. $\varepsilon$-Caprolactone (CL) and lactide are among the most prominent and intensively studied cyclic ester monomers for the synthesis of polyesters. The ROP 
of lactones can proceed via the anionic [15], cationic [16,17], or coordination route [18,19] depending on the catalytic system employed. In the past few decades, organometallic compounds of metals with Lewis acid properties, such as tin, zinc, or aluminum, as well as rare earth metals, such as yttrium and lanthanum, have been widely used for the synthesis of the related polyesters [20-23]. Brønsted acids, such as triflic acid [24] and phosphoric acid derivatives $[25,26]$, and organic bases, such as 4-(dimethylamino)pyridine [27], 1,5,7-triazabicyclo[4.4.0]dec-5-ene [28,29], and N-heterocyclic carbenes [30,31], which are organocatalytic systems, have attracted increasing attention in recent decades [32]. Stannous octoate complexes are the most well-established catalysts for the ROP of lactones because they are highly efficient and allow for good polymerization control [33]. However, there are several drawbacks attributed to the homogeneous nature of these systems, such as uncontrolled side reactions, high cost of the rare metals, potential toxicity of the residual metals, and the use of organic solvents that require tedious purification [34]. As opposed to homogeneous catalysts, solid catalysts can be easily separated or recycled from the resultant polymers, thus reducing the process cost and affording high-purity polymers. Therefore, heterogeneous systems, such as silica supports $[35,36]$, polystyrene supports [37], and microporous organic polymers [38] have been considered for the ROP of lactones. However, significant transesterification has been observed when employing silica supports [39] whereas polymer-supported catalysts mostly require the use of organic solvents [40]. Despite extensive investigation, reports on heterogeneous catalysis for the ROP of CL are surprisingly scarce, an effective heterogeneous system for the synthesis of polycaprolactone (PCL) thus is in demand.

A double metal cyanide (DMC) complex is a well-known heterogeneous catalytic system for the ROP of epoxides [41,42] and the copolymerization of epoxides with $\mathrm{CO}_{2}$ [43-45]. DMC catalysts possess Lewis acidic active sites within their matrix [46] and are highly stable; further, they can be effectively reused after separation from the products. Hence, these solid catalysts find promising application in the ROP of cyclic carboxylic esters. Herein, one-pot, solvent-free polymerization of CL was conducted using the DMC catalyst. Various initiators such as ethylene glycol (EG), propylene glycol (PG), glycerol (GL), and sorbitol (SB) can be employed to produce PCLs with $\alpha$ - and $\omega$-hydroxyl groups. The effect of the initiator on the polymeric structure and properties of the resultant polymers was studied. Note that the use of such initiators is not feasible in DMC-catalyzed epoxide polymerization because they can form stable dormant sites with the $\mathrm{Zn}$ atoms [47]. The effects of various ionic liquids (ILs) on the polymerization of $C L$ were also evaluated. Kinetic and mechanistic studies were performed to understand the DMC-catalyzed ROP of CL. Branched PCLs could also be prepared via the DMC-catalyzed copolymerization of $\mathrm{CL}$ with glycidol. The hydroxyl end-functionalized PCLs were utilized as soft segments to produce two important thermoplastic elastomers, poly(ester-ester) (PCL-TPE) and poly(ester-urethane) (PCL-TPU). The mechanical properties of the resultant PCL-TPE and PCL-TPU were compared with those of conventional TPEE and TPU counterparts produced by using PTMEG as a soft segment to prove the usefulness of PCLs.

\section{Results and Discussion}

\subsection{Polymerization of $C L$ Using DMC Catalyst}

The ROP of lactones using stannous octoate and rare earth metal complexes have been widely established for the synthesis of polyesters [21,22]. Generally, the polymerization was conducted under homogeneous conditions to control the product properties and minimize side reactions (i.e., inter- and intramolecular transesterification). In addition to homogeneous systems, heterogeneous DMC catalysts are potential candidates for the ROP of cyclic carboxylic esters due to their high Lewis acidity and high stability, thus, they can be reused after recovering from the products.

Herein, DMC-EAA, DMC-TBA, and DMC-IBN bearing ethyl acetoacetate (EAA), tertbutyl alcohol (TBA), and isobutyronitrile (IBN), respectively, as complexing agents, were employed for the ROP of CL. The characterization of these catalysts is given in Figure 
S1, Supporting Information. The structural formulas of the catalysts were determined using an inductively coupled plasma optical emission spectrometer, $(\mathrm{C}, \mathrm{H}, \mathrm{N})$ elemental analysis, and TGA (Table 1). The molar ratios of $\mathrm{Zn}^{2+}: \mathrm{Co}^{3+}: \mathrm{CN}^{-}$for the DMC-EAA (1.92:1:6.10) and DMC-IBN (1.94:1:4.87) are close to those reported for DMC catalysts (2:1:6) in the literature $[41,44]$. The character that distinguished the DMC catalysts of this study from the others was the use of EAA and IBN as organic complexing agents instead of TBA. The polymerization was attempted via a one-pot, solvent-free protocol under different reaction conditions using various initiators, such as PPG400, EG, PG, GL, and SB, and the monomer (M) to initiator (I) ratio was 10. Prescribed amounts of the catalyst and initiator were introduced into a reactor and purged with nitrogen for $30 \mathrm{~min}$. The reaction was then initiated by adding the monomer at $120^{\circ} \mathrm{C}$. To calculate the monomer conversion, the integral of the PCL signal (2.3 ppm) was divided by the sum of the integral of the PCL signal and the CL signal at $2.63 \mathrm{ppm}$. In the presence of the PPG400 initiator, PCL (MW $=1110 \mathrm{~g} \mathrm{~mol}^{-1} ; Ð=1.61$ ) was obtained (Table 2, run 1) with a monomer conversion of $85 \%$ after $24 \mathrm{~h}$. Notably, DMCcatalyzed ROP of CL did not proceed in the absence of a hydroxyl initiator, as confirmed by the absence of signals attributable to the polymer chains in the ${ }^{1} \mathrm{H}$ NMR spectrum of the reaction mixture after $24 \mathrm{~h}$ (see Figure S2, Supporting Information). Recently, Zhang and coworkers reported that the ROP of CL using DMC catalyst commonly requires the presence of an epoxide for polymerization [48]. However, these results indicated that the DMC-catalyzed ROP of CL can also occur via the insertion of the hydroxyl group from the initiator into the CL monomers.

Table 1. Elemental analysis of the DMC catalysts.

\begin{tabular}{|c|c|c|c|c|c|c|c|c|c|}
\hline \multirow[t]{2}{*}{ Catalyst } & \multicolumn{2}{|c|}{$\begin{array}{l}\text { ICP-Mass } \\
\text { (wt \%) }\end{array}$} & \multicolumn{3}{|c|}{$\begin{array}{l}\text { Elemental Analysis } \\
\text { (wt \%) }\end{array}$} & \multicolumn{3}{|c|}{$\begin{array}{c}\text { TGA } \\
\left(w t^{\%}\right)\end{array}$} & \multirow[t]{2}{*}{ Estimated Catalyst Formulation } \\
\hline & Zn & Co & C & $\mathbf{H}$ & $\mathbf{N}$ & CA & P123 & $\mathrm{H}_{2} \mathrm{O}$ & \\
\hline DMC-EAA & 21.5 & 10.1 & 30.5 & 3.0 & 14.6 & 14.8 & 25.2 & 0.8 & $\mathrm{Zn}_{1.92} \mathrm{Co}(\mathrm{CN})_{6.10} \cdot 0.66 \mathrm{EAA} \cdot 0.03 \mathrm{P} 123 \cdot 0.26 \mathrm{H}_{2} \mathrm{O} \cdot 0.07 \mathrm{Cl}^{-}$ \\
\hline DMC-TBA & 23.9 & 10.7 & 29.3 & 3.3 & 16.3 & 7.2 & 24.1 & 1.9 & $\mathrm{Zn}_{2.01} \mathrm{Co}(\mathrm{CN})_{6.41} \cdot 0.53 \mathrm{TBA} \cdot 0.02 \mathrm{P} 123 \cdot 0.58 \mathrm{H}_{2} \mathrm{O} \cdot 0.29 \mathrm{Cl}^{-}$ \\
\hline DMC-IBN & 24.6 & 11.4 & 32.3 & 3.6 & 13.2 & 32.0 & 28.1 & 2.9 & $\mathrm{Zn}_{1.94} \mathrm{Co}(\mathrm{CN})_{4.87} \cdot 2.39 \mathrm{IBN} \cdot 0.03 \mathrm{P} 123 \cdot 0.83 \mathrm{H}_{2} \mathrm{O} \cdot 0.14 \mathrm{Cl}^{-}$ \\
\hline
\end{tabular}

Table 2. Results for ROP of CL by DMC catalysts using various initiators (I).

\begin{tabular}{|c|c|c|c|c|c|c|c|c|c|c|}
\hline \multirow{2}{*}{$\operatorname{Run}^{1}$} & \multirow{2}{*}{ Catalyst } & \multirow{2}{*}{ I } & \multirow{2}{*}{$T_{\mathrm{p}}\left[{ }^{\circ} \mathrm{C}\right]$} & \multirow{2}{*}{$\begin{array}{l}t^{2} \\
{[\mathrm{~h}]}\end{array}$} & \multirow{2}{*}{$\begin{array}{l}x_{\mathrm{p}}{ }^{3} \\
{[\%]}\end{array}$} & \multirow{2}{*}{$M_{\mathrm{n}(\mathrm{Cal} .)^{4}}$} & \multirow{2}{*}{$\begin{array}{c}\text { MALDI-TOF } \\
M_{\mathrm{n}}\end{array}$} & \multicolumn{3}{|c|}{$M_{\mathrm{n}}$} \\
\hline & & & & & & & & NMR & GPC & $\boxplus$ \\
\hline 1 & DMC-EAA & PPG400 & 120 & 24 & 85 & 1380 & - & 1190 & 1110 & 1.61 \\
\hline 2 & DMC-EAA & EG & 120 & 24 & 90 & 1090 & 3290 & 3960 & 4000 & 1.35 \\
\hline 3 & DMC-EAA & PG & 120 & 24 & 92 & 1020 & - & 2690 & 2700 & 1.30 \\
\hline 4 & DMC-EAA & GL & 120 & 24 & 97 & 1200 & - & 2260 & 2100 & 1.05 \\
\hline 5 & DMC-EAA & EG & 160 & 6 & 94 & 1140 & - & 1610 & 1500 & 1.15 \\
\hline 6 & DMC-TBA & EG & 160 & 6 & 91 & 1100 & - & 1000 & 750 & 1.05 \\
\hline 7 & DMC-IBN & EG & 160 & 3 & 93 & 1120 & - & 1530 & 1200 & 1.08 \\
\hline 8 & DMC-EAA & PG & 160 & 8 & 94 & 1150 & 1240 & 1490 & 1500 & 1.26 \\
\hline 9 & DMC-EAA & GL & 160 & 8 & 96 & 1190 & 1540 & 2270 & 1700 & 1.54 \\
\hline 10 & DMC-EAA & SB & 160 & 8 & 95 & 1270 & 1465 & 4400 & 1600 & 1.16 \\
\hline
\end{tabular}

${ }^{1}$ Conditions: catalyst amount $=10 \mathrm{mg}\left([Z n]_{0}=30 \mathrm{mM}\right) ;[C L]_{0}=9 \mathrm{M} ;[C L]_{0} /[I]_{0}=10 ;{ }^{2}$ reaction time; ${ }^{3}$ monomer conversion, as determined from ${ }^{1} \mathrm{H}$ NMR; ${ }^{4}$ theoretical $M_{\mathrm{n}}, M_{\mathrm{n}(\mathrm{Cal} .)}=\left[\left([C L]_{0}-[C L]\right) \times 114.14 /[I]_{0}\right]+M_{(\mathrm{I})}$.

The polymerizations using EG, PG, and GL initiator were characterized by higher monomer conversion and gave PCLs with narrower $Ð$ values than those initiated by PPG400 (see Table 2, runs 1-4 and Figure S13, Supporting Information). The MW values of the EG-PCLs and PG-PCLs were estimated from the integration ratios of signals corresponding to the polymer backbone $\left(-\mathrm{CH}_{2}-\mathrm{CH}_{2}-\mathrm{O}-\right)$ at $4.06 \mathrm{ppm}$ and chain end $\left(-\mathrm{CH}_{2}-\right.$ $\mathrm{CH}_{2}-\mathrm{OH}$ ) at $3.64 \mathrm{ppm}$ in ${ }^{1} \mathrm{H}$ NMR spectra (see Figure 1 and Figures S3-S12, Supporting Information). It appeared that the $M_{\mathrm{n}}$ values of the PCLs obtained at $120^{\circ} \mathrm{C}$ are much higher than theoretically calculated, indicating that the PCL chains were longer than ex- 
pected because chain growing between polymer chains and monomers is favored versus initiation of the initiators with monomers. Furthermore, the DMC-catalyzed intermolecular transesterification may also occur, resulting in uncontrolled MW and broadened $Ð$ values. When the reaction temperature was increased to $160^{\circ} \mathrm{C}$, the polymerization time was shortened and the $M_{n}$ values of the resultant PCLs were much closer to the theoretical values, indicating that the polymerization was more efficient at higher temperatures (Table 2, runs 5-10). Among the DMC catalysts, DMC-IBN exhibited the highest activity with over $93 \%$ of monomer conversion within $3 \mathrm{~h}$. The catalytic activity decreased in the order of DMC-IBN > DMC-EAA > DMC-TBA (Figure S14, Supporting Information). These results indicate that the catalytic activity of the DMC catalysts toward ROP of CL could be tuned by modifying the organic complexing agents.

Characteristic signals corresponding to the polyester backbones of the resultant PCLs were clearly observed in the ${ }^{1} \mathrm{H}$ NMR spectra. The signals assigned to the methylene protons were located at 1.35-1.40, 1.62-1.66, 2.28-2.31, and 4.03-4.06 ppm, whereas those due to the methylene protons adjacent to the hydroxyl end group appeared at 3.61-3.65 ppm (see Figure 1 and Figures S3-S12, Supporting Information). For PPG400-PCL, the signals attributed to PPG400 initiator appeared at $1.12 \mathrm{ppm}$ (methyl protons) and 3.27-3.59 ppm (methine and methylene protons) (Figure S3, Supporting Information). For EG- and PG-PCLs, the signals corresponding to neat EG at $3.34 \mathrm{ppm}$ (methylene) shifted to $4.28 \mathrm{ppm}$ whereas the signals of methyl (1.16 ppm), methylene (3.40/3.62 ppm), and methine (3.91 ppm) protons of the neat PG shifted to $1.25,4.15$, and $5.13 \mathrm{ppm}$, respectively, upon polymerization (Figure 1a,b, Figures S4, S5 and S7-S10 in Supporting Information). The ${ }^{1} \mathrm{H}$ NMR spectra of EG- and PG-PCLs also indicated the absence of non-substituted and mono-substituted EG and PG after reaction, which would be a significant difference with usual organometallic catalysts [49]. In case of GL-PCLs, the signals assigned to the methylene protons of the reacted GL initiator located at 4.15-4.35 ppm whereas signals of the methine protons appeared at $5.26 \mathrm{ppm}$ (see Figure 1c, Figures S6 and S11, Supporting Information). When the reaction was performed in the presence of the SB initiator, signals attributed to the methyl protons of the esterified primary carbon atoms (a) were located at $4.10-4.40 \mathrm{ppm}$, while those corresponding to the methine protons of the esterified secondary carbon atoms $(\mathrm{b}, \mathrm{c})$ appeared at $4.85-5.35 \mathrm{ppm}$, indicating that both primary and secondary hydroxyl groups initiated the polymerization (see Figure S12). However, due to the relatively high activity of the primary hydroxyl compared to secondary hydroxyl of the sorbitol, a mixture of PCLs with miktoarm polymer architectures may be generated [11].

The absolute MWs of the PCLs obtained at $160^{\circ} \mathrm{C}$ were determined by matrix-assisted laser desorption ionization-time-of-flight (MALDI-TOF) measurements. Figures S15-S17 in the Supporting Information show that the $M_{\mathrm{n}}$ values of the PCLs (1240-1540 $\mathrm{g} \mathrm{mol}^{-1}$ ) are slightly lower than those obtained from NMR and GPC analyses (1500-1700 $\mathrm{g} \mathrm{mol}^{-1}$ ). MALDI-TOF spectra also indicated that PCLs obtained at $160{ }^{\circ} \mathrm{C}$ were predominantly initiated by the initiators used with minimal transesterification, at least at low molecular weights. In addition, no conspicuous signals attributed to the formation of macrocycles were observed.

The recyclability of DMC-EAA catalyst for the ROP of CL was investigated at $160{ }^{\circ} \mathrm{C}$ using EG initiator. The catalyst shows no remarkable decrease in activity even after being reused for five cycles (Figure S18). FTIR spectra of the catalyst collected after reaction show that the characteristic signals of the DMC-EAA at $2200 \mathrm{~cm}^{-1}(v(C \equiv N))$ and $478 \mathrm{~cm}^{-1}$ $(\delta(\mathrm{Co}-\mathrm{CN}))$ remained, while the $v(\mathrm{C}=\mathrm{O})$ peak at $1725 \mathrm{~cm}^{-1}$ disappeared. This indicates that the coordinated complexing agent molecules were removed after reaction. The diffraction pattern of the catalyst after recovery shows that the reflection assigned to the monoclinic phase at 23.7 was relatively collapsed, whereas other reflections at $2 \theta=14.1-21.6^{\circ}$ remained. These results indicate that the catalyst particles were subjected to fracture after 5 recycles. Note that the catalyst can be simply recovered and reused by centrifugation and washing with chloroform without further reactivation by chemical treatment. Although DMC catalyst exhibits lower activity compared with the conventional homogeneous systems, there 
is still room for further optimization and potential for industrial applications due to the simple preparation and high stability/reusability of these catalysts.

(a)
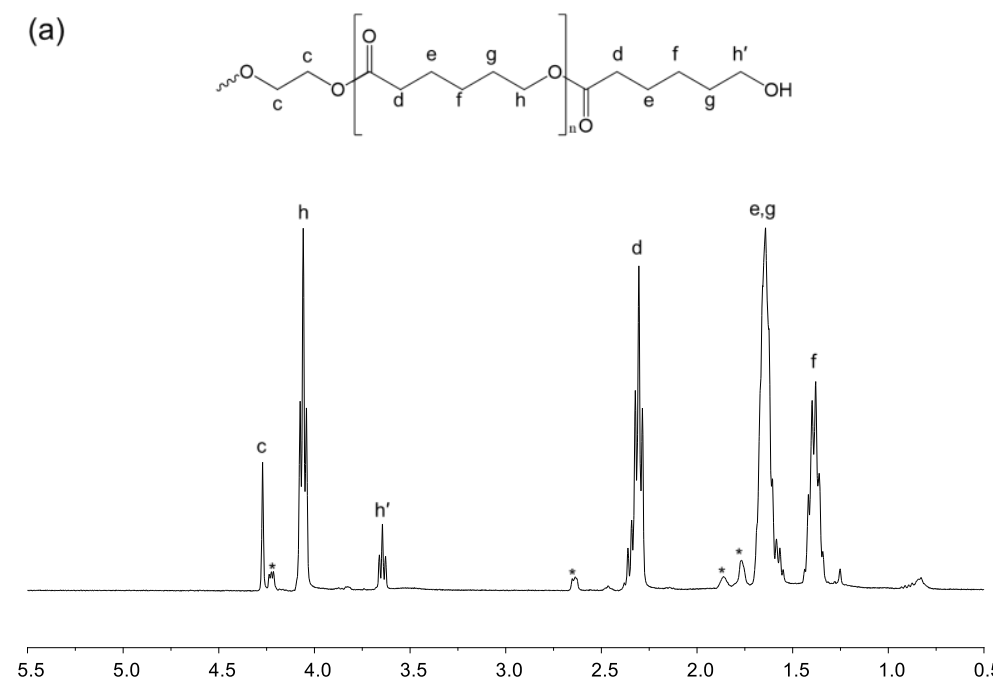

(b)
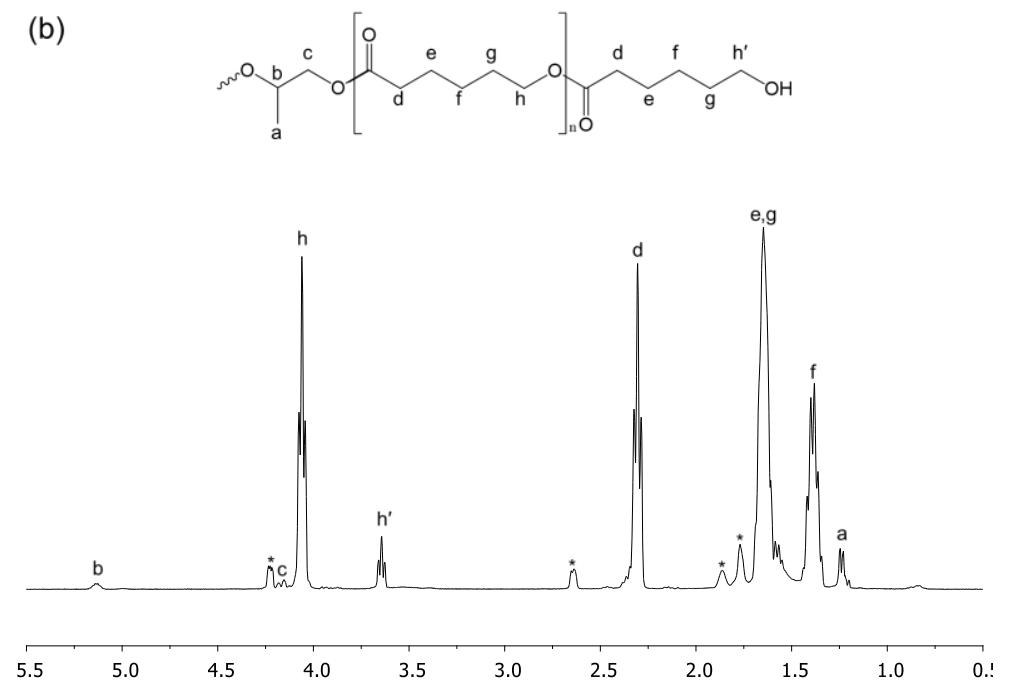

(c)
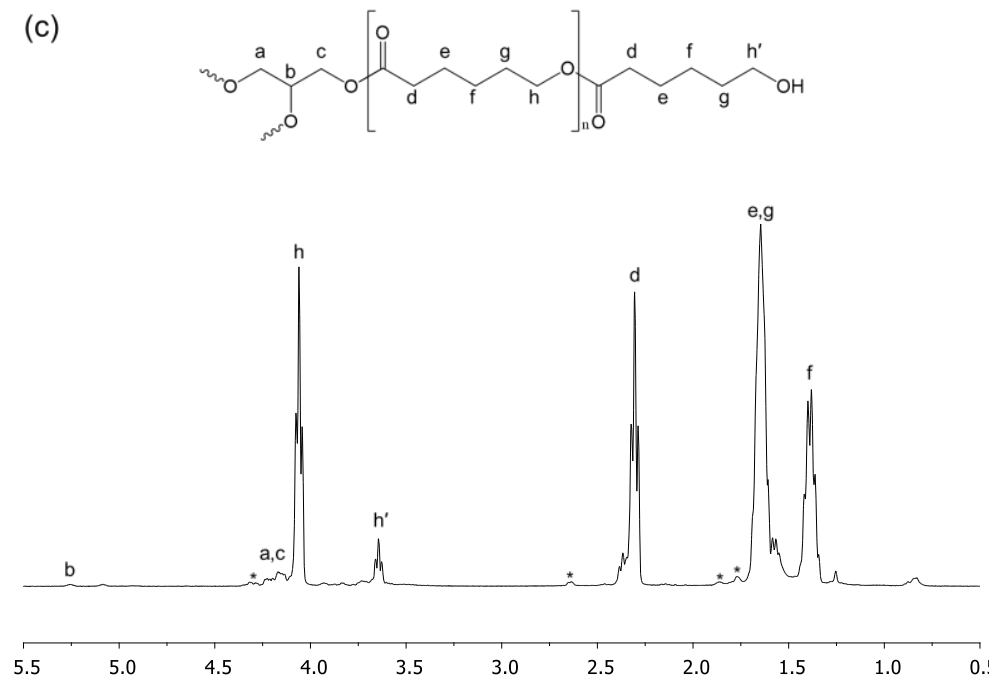

Figure 1. ${ }^{1} \mathrm{H}$ NMR spectra $\left(400 \mathrm{MHz}, \mathrm{CDCl}_{3}\right)$ of the crude reaction mixture of $\mathrm{CL}$ polymerization using various initiators: (a) EG, (b) PG, and (c) GL (runs 5, 8, and 9 of Table 2). * denotes the residual monomer signals. 
The ROPs of CL were then conducted at $160{ }^{\circ} \mathrm{C}$ with different $\mathrm{CL}$ to initiator ratios $\left([C L]_{0} /[I]_{0}\right)$ using the DMC-EAA catalyst. As shown in Table 3, PCLs with MWs in the range of $950-10,100 \mathrm{~g} \mathrm{~mol}^{-1}$ and with various $Ð$ values (1.10-1.87) depending on the type of initiator were successfully synthesized. GPC analysis showed that the MWs of the resultant PCLs increased with increasing $[C L]_{0} /[I]_{0}$ ratio (see Figure $2 \mathrm{a}$, Figures S19 and S20 in the Supporting Information). For PG- and GL-PCLs, a significant difference between the theoretical and GPC $M_{\mathrm{n}}$ values and a remarkable increase in the dispersity was experienced when the $[C L]_{0} /[I]_{0}$ ratio was close to 100 , most likely due to intermolecular transesterification reactions (Table 3, run 6-15). When using SB as the initiator, the experimental number-average MW $\left(M_{n}\right)$ values increased linearly with the $[C L] /[S B]$ ratio and were in good agreement with the calculated values, while the $Đ$ values remained narrow, indicating a higher degree of control comparing to PG and GL (Table 3, runs $1-5$ and Figure $2 b$ ).

Table 3. Results for ROP of CL by DMC-EAA catalyst using various $[C L]_{0} /[I]_{0}$ ratios.

\begin{tabular}{|c|c|c|c|c|c|c|c|}
\hline \multirow{2}{*}{ Run ${ }^{1}$} & \multirow{2}{*}[CL]{$_{0} /[I]_{0}$} & \multirow{2}{*}{ I } & \multirow{2}{*}{$\begin{array}{c}T \\
{[\mathrm{~h}]}\end{array}$} & \multirow{2}{*}{$\begin{array}{l}x_{\mathrm{p}}{ }^{2} \\
{[\%]}\end{array}$} & \multirow{2}{*}{$M_{\mathrm{n}(\mathrm{Cal} .)^{3}}$} & \multicolumn{2}{|c|}{ GPC } \\
\hline & & & & & & $M_{\mathrm{n}}$ & $\bigoplus$ \\
\hline 1 & 100 & SB & 12 & 94 & 10,620 & 10,100 & 1.21 \\
\hline 2 & 50 & SB & 10 & 93 & 5420 & 5900 & 1.20 \\
\hline 3 & 20 & SB & 8 & 95 & 2150 & 3200 & 1.15 \\
\hline 4 & 10 & SB & 8 & 97 & 1110 & 1600 & 1.16 \\
\hline 5 & 5 & SB & 8 & 97 & 550 & 950 & 1.10 \\
\hline 6 & 100 & PG & 12 & 92 & 10,500 & 4800 & 1.68 \\
\hline 7 & 50 & PG & 10 & 95 & 5420 & 3100 & 1.27 \\
\hline 8 & 20 & PG & 8 & 95 & 2170 & 2200 & 1.23 \\
\hline 9 & 10 & PG & 8 & 94 & 1070 & 1500 & 1.26 \\
\hline 10 & 5 & PG & 8 & 96 & 550 & 1050 & 1.25 \\
\hline 11 & 100 & GL & 12 & 92 & 10,940 & 7500 & 1.87 \\
\hline 12 & 50 & GL & 10 & 92 & 5570 & 4800 & 1.62 \\
\hline 13 & 20 & GL & 8 & 93 & 2310 & 3200 & 1.36 \\
\hline 14 & 10 & GL & 8 & 96 & 1190 & 1700 & 1.54 \\
\hline 15 & 5 & GL & 8 & 97 & 650 & 1100 & 1.15 \\
\hline
\end{tabular}

${ }^{1}$ Conditions: DMC-EAA $=10 \mathrm{mg}\left([Z n]_{0}=30 \mathrm{mM}\right),[C L]_{0}=9 \mathrm{M} ; T_{\mathrm{p}}=160{ }^{\circ} \mathrm{C} ;{ }^{2}$ monomer conversion determined by ${ }^{1} \mathrm{H} \mathrm{NMR} ;{ }^{3}$ theoretical $M_{n}, M_{\mathrm{n} \text { (Cal.) }}=\left[\left([C L]_{0}-[C L]\right) \times 114.14 /[I]_{0}\right]+M_{(\mathrm{I})}$.
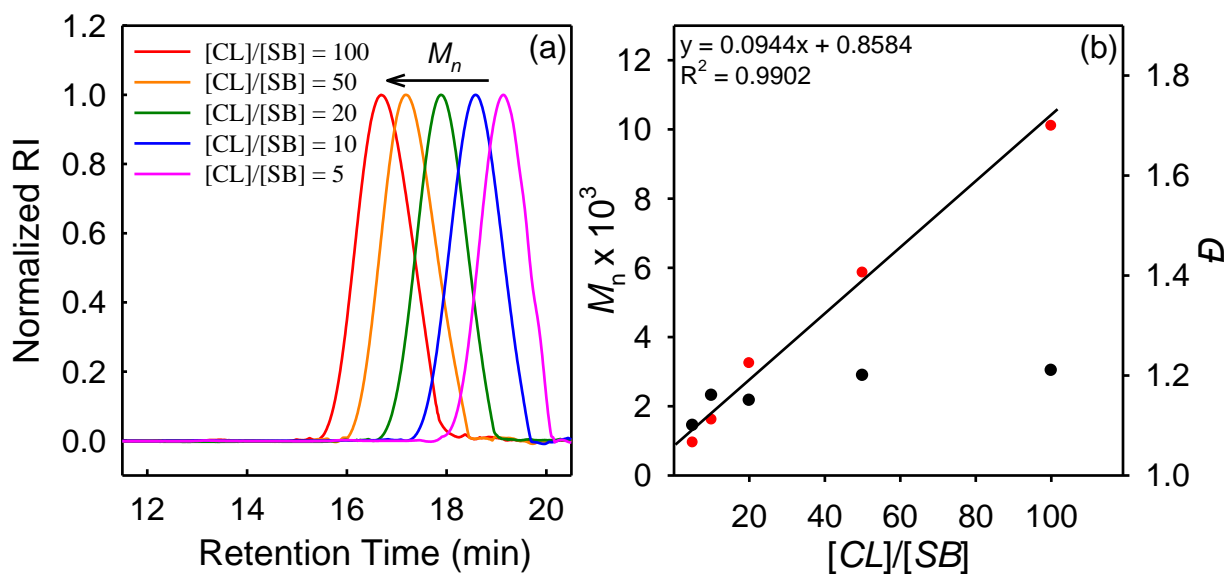

Figure 2. (a) GPC curves of the PCLs and (b) plot of $M_{\mathrm{n}}$ and $Đ$ versus [CL]/[SB] obtained using various amounts of SB initiator. Conditions: DMC-EAA $=10 \mathrm{mg}\left([\mathrm{Zn}]_{0}=30 \mathrm{mM}\right),[C L]_{0}=9 \mathrm{M}$, $T_{\mathrm{p}}=160^{\circ} \mathrm{C}$.

The polymerization of CL initiated by the PG and GL initiators was further investigated using an $\mathrm{IL}$ at $160^{\circ} \mathrm{C}\left([I L]_{0} /[Z n]_{0}=2.5\right)$. In the presence of $\mathrm{BMIMCl}$, the $Ð$ values of the resultant 
PCLs remained narrow when increasing the $[C L]_{0} /[I]_{0}$ ratio; however, the monomer conversion was significantly reduced, and the MW values were lower than those obtained without using any IL (Table 3, runs 6-15; Table S1, runs 1-5; Table S2, runs 1-5; and Figures S21-S23 in the Supporting Information). The effect of the $\mathrm{BMIMCl}$ to catalyst ratio $\left([\mathrm{IL}]_{0} /[\mathrm{Zn}]_{0}\right)$ on the polymerization of CL was also investigated, even though it had negligible influence on the polymerization (Table S1, runs 6-10 and Figure S24 in the Supporting Information). The ROPs of $\mathrm{CL}$ in the presence of other ILs, such as TMAB, TEAB, and TDAB, were also investigated. However, the monomer conversion was much lower $\left(x_{\mathrm{p}}<30 \%\right)$ than that observed when using BMIMCl (see Table S2, runs 4, 6-8, Supporting Information). The strong interaction between $\mathrm{Zn}$ and the counterions of the IL may prevent the coordination of incoming monomers to the active sites, resulting in a lower reaction rate.

\subsection{Kinetic Studies of the DMC-Catalyzed ROP of CL}

To determine the polymerization kinetics, the ROPs of CL were further investigated using the DMC-EAA and DMC-IBN catalysts in the presence of EG, GL, and SB initiators. During the polymerization, the reaction mixture was sampled at different intervals (0.5-4 h) for NMR and GPC analyses. The ${ }^{1} \mathrm{H}$ NMR spectra of monomer consumption versus time showed that the signals attributed to the methylene protons of the CL monomer at $1.80,2.65$, and $4.21 \mathrm{ppm}$ diminished while those corresponding to the polyester backbone at 1.40, 1.65, 2.35, 3.65, and 4.08 ppm became pronounced (Figures S25-S29, Supporting Information). Furthermore, the signals of the neat EG initiator at $3.74 \mathrm{ppm}$ decrease with time while the signal of the esterified EG at 4.28 ppm increase simultaneously, demonstrating that the ROP of CL was initiated by the hydroxyl groups of the initiator (Figure 3). The monomer conversion at four different polymerization temperatures was plotted as a function of time to determine the reaction rate. The linear relationship between $\ln \left([C L]_{0} /[C L]\right)$ and time (Figure $4 \mathrm{a}$ ) revealed that the DMC-catalyzed ROP of CL proceeded with first-order dependence on the CL concentration, without an induction period. The reaction rate constants $\left(k_{\mathrm{p}}\right)$ were derived from the slope, and the activation energy $\left(E_{\mathrm{a}}\right)$ was then calculated from the Arrhenius plot (Figure $4 \mathrm{~b}$ ) using Equation (1). The $E_{\mathrm{a}}$ value of DMC-EAA $\left(76.67 \mathrm{~kJ} \mathrm{~mol}^{-1}\right)$ is relative higher than those obtained using other rare earth coordination catalysts, such as neodymium complexes (59.4 $\mathrm{kJ} \mathrm{mol}^{-1}$ ) [20], scandium complexes (26.5-55.0 $\mathrm{kJ} \mathrm{mol}^{-1}$ ) [23], most probably due to transport/diffusion limitations of the solid catalyst. The reaction rate constants and activation energy are summarized in Table 4.

$$
k_{\mathrm{p}}=\mathrm{Ae}^{\left(-E_{\mathrm{a}} / \mathrm{RT}\right)} \ln k_{\mathrm{p}}-\frac{E_{\mathrm{a}}}{\mathrm{RT}}+\ln \mathrm{A}
$$

The evolution of the MWs of the PCLs obtained using GL and SB initiators was investigated using GPC analyses. $M_{\mathrm{n}}$ and $Ð$ were plotted as functions of the monomer conversion $\left(x_{\mathrm{p}}\right)$ and polymerization time. At 130 and $140^{\circ} \mathrm{C}$, the MW of the GL-PCL increased linearly with the monomer conversion and reaction time, while $Ð$ slightly increased (1.01-1.41) at a later stage of the polymerization (Figure 5, Figures S30 and S31 in the Supporting Information). At 150 and $160^{\circ} \mathrm{C}, Ð$ was significantly broadened when the monomer conversion was greater than 90\% (see Figures S32-S35, Supporting Information), because of unwanted intermolecular transesterification, as observed in the ROP of lactones initiated by other rare earth-based catalysts [50,51].

In the polymerization using the SB initiator, the MW of the PCL increased linearly with time, while $Ð$ remained narrow, indicating a high degree of control even at $160{ }^{\circ} \mathrm{C}$ (Figure 6). A two-step monomer addition ROP of CL was performed at $160{ }^{\circ} \mathrm{C}$ using the SB initiator to ensure that the polymerization was controlled. After polymerization for $12 \mathrm{~h}$, an additional monomer was added to the reaction mixture and allowed to react for further $12 \mathrm{~h}$. The GPC results in Figure 7 show that the MW increased from 1500 to $2850 \mathrm{~g} \mathrm{~mol}^{-1}$, while $Đ$ remained narrow (1.19-1.24). These results suggested that the DMC-catalyzed ROP of CL proceeded via a chain growth mechanism with living features. 


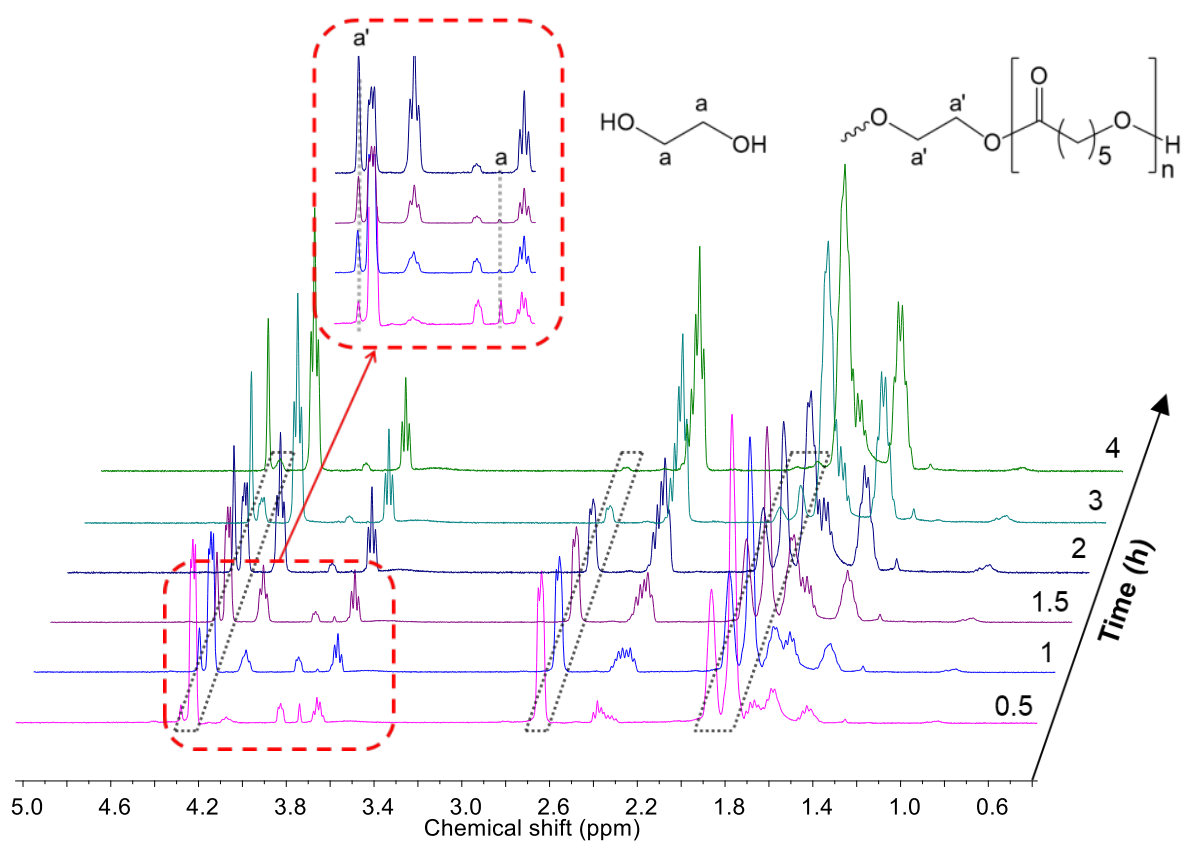

Figure 3. ${ }^{1} \mathrm{H}$ NMR $\left(400 \mathrm{MHz}, \mathrm{CDCl}_{3}\right)$ spectra of the PCL collected at different intervals. Conditions: $\mathrm{DMC}-\mathrm{IBN}=10 \mathrm{mg}\left([\mathrm{Zn}]_{0}=30 \times \mathrm{mM}\right),[C L]_{0}=9 \mathrm{M},[C L]_{0} /[E G]_{0}=10, \mathrm{~T}_{p}=160^{\circ} \mathrm{C}$. Dash lines denote the monomer signals.
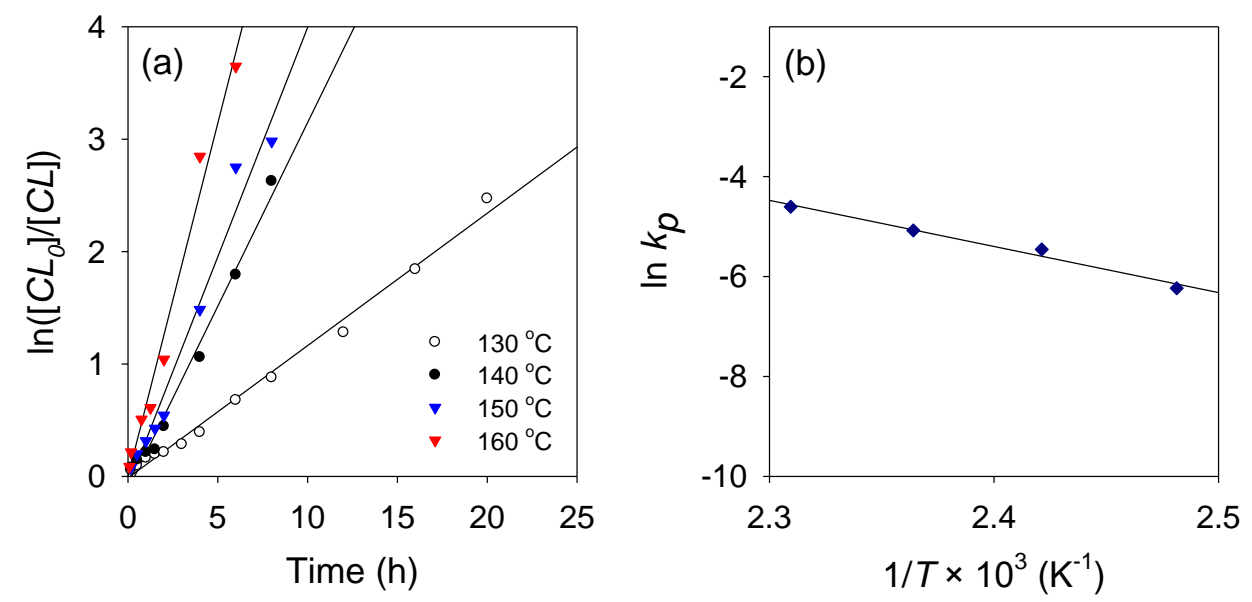

Figure 4. (a) First-order time-conversion plots of the batch polymerization of CL at different temperatures and (b) Arrhenius plot of the batch polymerization of CL. Conditions: DMC-EAA $=10 \mathrm{mg}$ $\left([\mathrm{Zn}]_{0}=30 \mathrm{mM}\right),[C L]_{0}=9 \mathrm{M},[C L]_{0} /[G L]_{0}=20$.

Table 4. Kinetic results for the ROP of CL at different temperatures using DMC-EAA catalyst (Zn) and GL initiator.

\begin{tabular}{|c|c|c|c|c|c|c|c|}
\hline \multirow{2}{*}{ Run ${ }^{1}$} & \multirow{2}{*}{$\begin{array}{l}T_{\mathrm{p}}{ }^{2} \\
{\left[{ }^{\circ} \mathrm{C}\right]}\end{array}$} & \multirow{2}{*}{$\begin{array}{c}T \\
{[\mathrm{~h}]}\end{array}$} & \multirow{2}{*}{$\begin{array}{l}x_{\mathrm{p}}{ }^{3} \\
{[\%]}\end{array}$} & \multirow{2}{*}{$\underset{\left[\min ^{-1}\right]}{k_{\mathrm{p}}^{4} \times 10^{3}}$} & \multirow{2}{*}{$\begin{array}{c}E_{\mathrm{a}}^{5} \\
{\left[\mathrm{~kJ} \mathrm{~mol}^{-1}\right]}\end{array}$} & \multicolumn{2}{|c|}{ GPC } \\
\hline & & & & & & $M_{\mathrm{n}}$ & 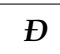 \\
\hline 1 & 130 & 20 & 91.55 & 1.96 & & 3400 & 1.41 \\
\hline 2 & 140 & 10 & 95.00 & 4.26 & & 3500 & 1.58 \\
\hline 3 & 150 & 8 & 94.92 & 6.24 & 76.67 & 3000 & 1.76 \\
\hline 4 & 160 & 6 & 93.77 & 10.00 & & 2500 & 1.78 \\
\hline
\end{tabular}

${ }^{1}$ Conditions: DMC-EAA $=10 \mathrm{mg}\left([\mathrm{Zn}]_{0}=30 \mathrm{mM}\right),[C L]_{0}=9 \mathrm{M},[C L]_{0} /[G L]_{0}=20 ;{ }^{2}$ polymerization temperature; ${ }^{3}$ monomer conversion, as determined by ${ }^{1} \mathrm{H}$ NMR; ${ }^{4}$ rate constant determined from the time-conversion plots in Figure $4 ;{ }^{5}$ overall activation energy. 

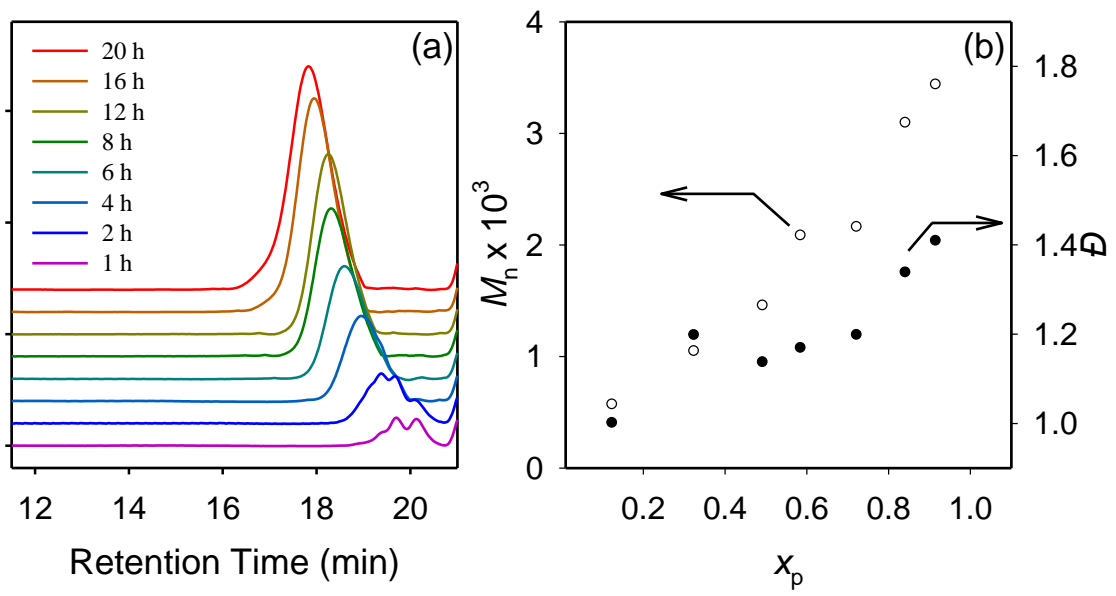

Figure 5. (a) GPC curves of PCL and (b) plots of $M_{n}$ and $Đ$ versus monomer conversion $\left(x_{\mathrm{p}}\right)$ collected at different intervals. Conditions: DMC-EAA $=10 \mathrm{mg}\left([\mathrm{Zn}]_{0}=30 \mathrm{mM}\right),[C L]_{0}=9 \mathrm{M},[C L]_{0} /[G L]_{0}=20$, $T_{\mathrm{p}}=130^{\circ} \mathrm{C}$.
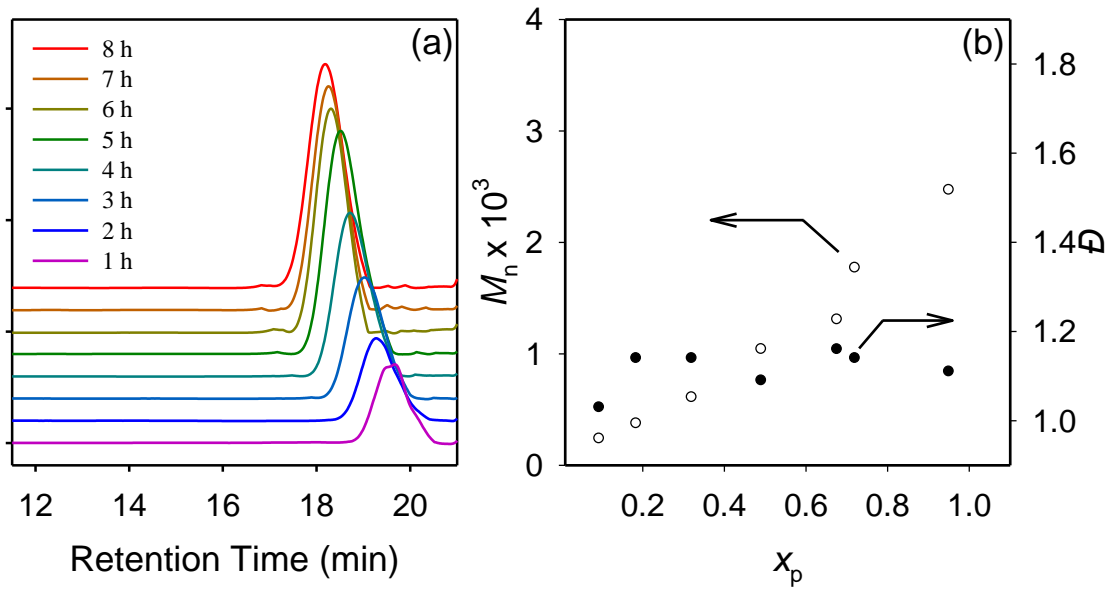

Figure 6. (a) GPC curves of PCL and (b) plots of $M_{\mathrm{n}}$ and $Đ$ versus monomer conversion $\left(x_{\mathrm{p}}\right)$ collected at different intervals. Conditions: DMC-EAA $=10 \mathrm{mg}\left([\mathrm{Zn}]_{0}=30 \mathrm{mM}\right),[C L]_{0}=9 \mathrm{M},[C L]_{0} /[S B]_{0}=20$, $T_{\mathrm{p}}=160^{\circ} \mathrm{C}$.

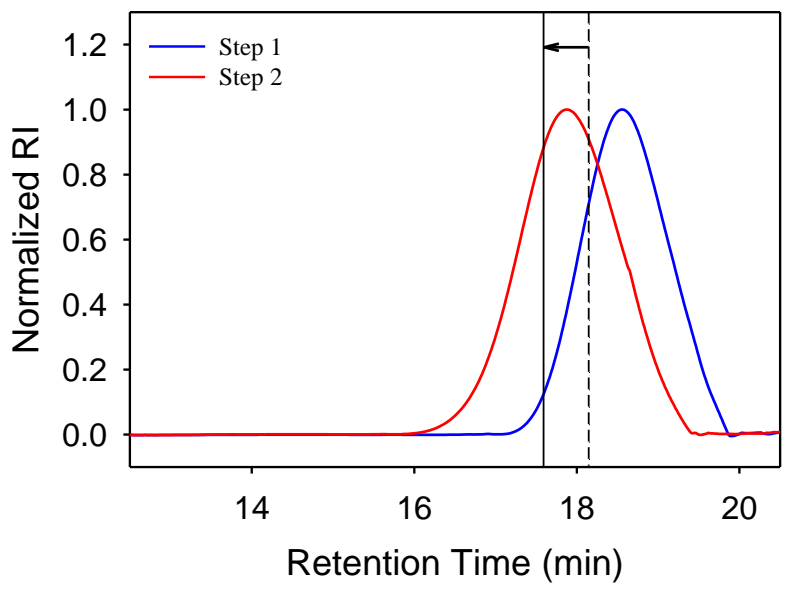

Figure 7. GPC curves of PCL collected during 2-step monomer addition. Conditions: DMC-EAA = $10 \mathrm{mg}$ $\left([\mathrm{Zn}]_{0}=30 \mathrm{mM}\right),[C L]_{0}=9 \mathrm{M},[C L]_{0} /[S B]_{0}=10, T_{\mathrm{p}}=160^{\circ} \mathrm{C}$. 
In the DMC-catalyzed ROP of epoxides (i.e., PO, glycidol), the active sites involve cationic coordination between zinc and the monomer, and the polymerization can proceed via both coordinative and cationic mechanisms [52,53]. Accordingly, the cationic pathway is expected when no initiator is used or when the amount of initiator is negligible, whereas the coordinative mechanism is favored in the presence of the hydroxyl initiator. On the other hand, the ROP of CL using a DMC catalyst only occurs in the presence of a hydroxyl initiator (vide supra). Kinetic studies clearly indicated that the polymerization of CL proceeds via a simple coordinative mechanism. As shown in Scheme 1, the polymerization is initiated by the nucleophilic attack of the hydroxyl initiator on the carbonyl group of the coordinated CL to generate the propagating species with a hydroxy-terminated chain-end, along with insertion of the monomer unit. The reaction then proceeds until the monomer is completely consumed. Nevertheless, intermolecular transesterification is observed at the later stage of polymerization, especially at elevated temperatures and high monomer conversions.

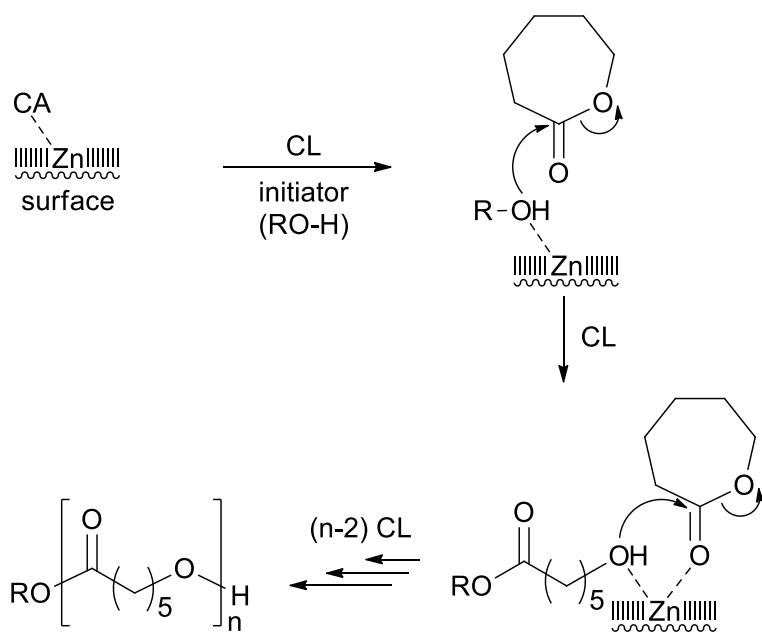

$\mathrm{CA}=$ organic complexing agent<smiles>CC(O)CO</smiles>

$\mathrm{R}-\mathrm{OH}=$<smiles>OCC(O)C(O)C(O)C(O)CO</smiles>

Scheme 1. Proposed mechanism for the DMC-catalyzed ROP of CL.

\subsection{Copolymerization of CL with Glycidol Using DMC-EAA Catalyst}

The copolymerization of $C L$ with glycidol was investigated for various $\mathrm{CL} /$ glycidol ratios at $160^{\circ} \mathrm{C}$ using the $\mathrm{DMC}$ catalyst. The latent cyclic $\mathrm{AB}_{2}$-type glycidol monomer can possibly coordinate to the metal sites via the hydroxyl or oxirane oxygen; thus, glycidol may also act as an initiator and branching monomer (see Scheme S1, Supporting Information). As shown in the ${ }^{1} \mathrm{H}$ NMR spectra in Figures S36-S38 in the Supporting Information, the characteristic signal of the glycidol units appeared at $3.40-3.90 \mathrm{ppm}$ along with the signals of the CL segments, and its intensity increased with increasing glycidol feed ratio. The formation of the branched polyester was also confirmed by $2 \mathrm{D}$ and ${ }^{13} \mathrm{C}$ NMR spectra (see Figures S39 and S40, Supporting Information). Diffusion-ordered spectroscopy (DOSY) NMR showed that the diffusion coefficient values for protons corresponding to the polyglycidol core is relatively close to those regarding the PCL chains. In the ${ }^{1} \mathrm{H}$ 
NMR spectrum, the triplet signal at $3.64 \mathrm{ppm}$ that decreases with increasing of glycidol in the feed are assigned to the terminal groups of CL whereas the signals at 3.79, 2.84, and 3.15 ppm also indicated that the copolymers were partially end-capped with epoxy groups, as observed in the DMC-catalyzed ROMBP of glycidol [53]. The merging of the epoxy end group when the reaction time was increased (Figure S41, Supporting Information) indicated that these terminal epoxide units underwent ring opening by other oligomeric species to generate higher-MW PCL fractions. These high-MW fractions could be traced from the GPC curves of the PCLs when the glycidol feed ratio was increased (Figure S42, Supporting Information). Accordingly, $M_{\mathrm{n}}$ decreased from 5300 to $2800 \mathrm{~g} \mathrm{~mol}^{-1}$, whereas $Đ$ was significantly broadened from 1.19 to 3.77 when the glycidol feed ratio was increased to CL (Table 5).

Table 5. Results for copolymerization of CL with glycidol (G) using DMC catalyst (Zn).

\begin{tabular}{|c|c|c|c|c|c|c|c|}
\hline \multirow{2}{*}{ Run ${ }^{1}$} & \multirow{2}{*}[CL]{$_{0} /[G]_{0}$} & \multicolumn{2}{|c|}{$\begin{array}{l}x_{p}{ }^{2} \\
{[\%]}\end{array}$} & \multicolumn{2}{|c|}{$\begin{array}{c}F^{3} \\
{[\%]}\end{array}$} & \multicolumn{2}{|c|}{ GPC } \\
\hline & & CL & G & CL & G & $M_{n}$ & $\bigoplus$ \\
\hline 1 & $7: 3$ & 99 & 98 & 76 & 24 & 5300 & 1.19 \\
\hline 2 & $6: 4$ & 99 & 98 & 63 & 37 & 3100 & 3.34 \\
\hline 3 & $5: 5$ & 99 & 97 & 51 & 49 & 2800 & 3.77 \\
\hline
\end{tabular}

${ }^{1}$ Conditions: DMC-EAA $=10 \mathrm{mg}\left([Z n]_{0}=30 \mathrm{mM}\right),[C L]_{0}=5 \mathrm{M}, T_{\mathrm{p}}=160{ }^{\circ} \mathrm{C} ;{ }^{2}$ monomer conversion determined by ${ }^{1} \mathrm{H}$ NMR; ${ }^{3}$ copolymer content determined by ${ }^{1} \mathrm{H}$ NMR.

\subsection{Synthesis of PCL-TPE and PCL-TPU}

The EG-PCL-1000 and PG-PCL-1000 diols $\left(F=2, M_{n} \approx 1000 \mathrm{~g} \mathrm{~mol}^{-1}\right)$ produced by EG and PG initiators, respectively, were employed as the soft segments to prepare PCL-TPEs. The PCL-TPEs with 50\% hard segment were synthesized via a one-pot, two-step protocol. The above polyols were reacted with the hard segments formed by the transesterification of NDC with BD (chain extender) at $160-210{ }^{\circ} \mathrm{C}$ using TBT catalyst (for synthesis procedure, see Scheme S2, Supporting Information).

Characteristic signals assigned to the hard segments were confirmed by ${ }^{1} \mathrm{H}$ NMR spectra. As shown in Figures S43 and S44 in the Supporting Information, signals attributed to the aromatic protons of the NDC and methylene protons of BD appeared at 7.98-8.61 ppm and 2.05/4.51 ppm, respectively, whereas the signals corresponding to the methylene protons of PCL locate at 1.37-1.84, 2.35, and 4.06-4.38 ppm. The conventional poly(ether ester) elastomer using PTMEG-1000 diol $\left(M_{n} \approx 1000 \mathrm{~g} \mathrm{~mol}^{-1}\right)$ as a soft segment was also prepared for comparison (Figure S45, Supporting Information).

The PCL-based TPUs targeting 50\% hard segment were prepared via a two-step procedure using PG-PCL diol. The isocyanate-terminated prepolymer was first prepared by reacting PG-PCL-1000 diol with HDI, followed by chain extended using BD (Scheme S3, Supporting Information). Likewise, conventional polyurethane ether elastomer prepared using PTMEG-1000 diol was obtained for comparison.

As shown in Figures S46 and S47 in the Supporting Information, ${ }^{1} \mathrm{H}$ NMR spectra of the resultant PCL-TPU and TPU indicate the formation of urethane linkages (broad signal at $4.78 \mathrm{ppm}$ ). For PCL-TPU, signals at 1.49 and $3.15 \mathrm{ppm}$ correspond to the methylene protons of HDI whereas signals attributed to the methylene protons of BD at 1.67 and $4.06 \mathrm{ppm}$ are over-lapped by the peaks of PCL chains. The disappearance of the methylene protons adjacent to the hydroxyl end group at $3.64 \mathrm{ppm}$ indicates that the hydroxyl-terminated groups were completely consumed.

The resultant TPUs were further characterized by FT-IR analyze (Figure S48, Supporting Information). The disappearance of the isocyanate peak at $2262 \mathrm{~cm}^{-1}$ along with the existence of the urethane linkage signals at $3327 \mathrm{~cm}^{-1}(-\mathrm{NH}), 1722 / 1680 \mathrm{~cm}^{-1}(-\mathrm{C}=\mathrm{O})$, $1540 \mathrm{~cm}^{-1}$ (-NH-CO) clearly confirm successful synthesis of the TPUs [54].

The thermal stability of PCL-TPE and PCL-TPU samples was determined by TGA analysis. All the PCL-TPEs exhibit complete degradation at $400-405{ }^{\circ} \mathrm{C}$ (Figure S49, Supporting 
Information). For the TPU samples, PCL-TPU completely decomposes at $305^{\circ} \mathrm{C}$, whereas TPU shows a two-stage degradation: i.e., an initial degradation at $305^{\circ} \mathrm{C}$ and the second decomposition at $405{ }^{\circ} \mathrm{C}$ (Figure S50, Supporting Information). Thermal transitions of the PCL-TPEs and PCL-TPU were also determined by DSC. As shown in Figure S51 in the Supporting Information, all PCL-TPEs exhibit similar melting temperature $\left(T_{\mathrm{m}} \approx 93^{\circ} \mathrm{C}\right)$ and crystallization temperature $\left(T_{\mathrm{c}} \approx 56^{\circ} \mathrm{C}\right)$. During the second heating scan, only PCLTPE-3 shows a cold crystallization $\left(T_{\mathrm{cc}}\right)$ peak at $26^{\circ} \mathrm{C}$. The glass transition temperature $\left(T_{\mathrm{g}}\right)$ values decrease in the order of PCL-TPE- $1\left(4^{\circ} \mathrm{C}\right)>$ PCL-TPE- $2\left(-10^{\circ} \mathrm{C}\right)>\operatorname{TPEE}\left(-21^{\circ} \mathrm{C}\right)$. The $T_{\mathrm{g}}$ values obtained for TPU and PCL-TPU are -65 and $-46^{\circ} \mathrm{C}$, respectively (Figure S52, Supporting Information).

The mechanical properties of PCL-TPE and PCL-TPU samples were evaluated using a universal testing machine and the resultant stress-strain curves are shown in Figure 8. All the PCL-TPE samples exhibit soft plastic stress-strain behavior with low tensile yield strength (5-7 MPa) (Figure 8a). PCL-TPE-1 and PCL-TPE-3 (based on EG-PCL and PG-PCL) reveal surprisingly high tensile strength of 47-64 MPa, far exceeding the value for the conventional TPEE (25 MPa). The tensile strength and elongation values of PCL-TPE-3 $(64 \mathrm{MPa} / 1060 \%)$ are higher than those obtained for PCL-TPE-1 (47 MPa/950\%). The mechanical properties of the PCL-TPE-2, PCL-TPE-4, and PCL- TPE-5 produced by PG-PCLs of different MWs of $\approx 500, \approx 2000$, and $\approx 3000 \mathrm{~g} \mathrm{~mol}^{-1}$, respectively, were also investigated. As shown in Figure S53 in the Supporting Information, the stress and strain of the PCL-TPEs slightly increase with increasing MW of PCLs.
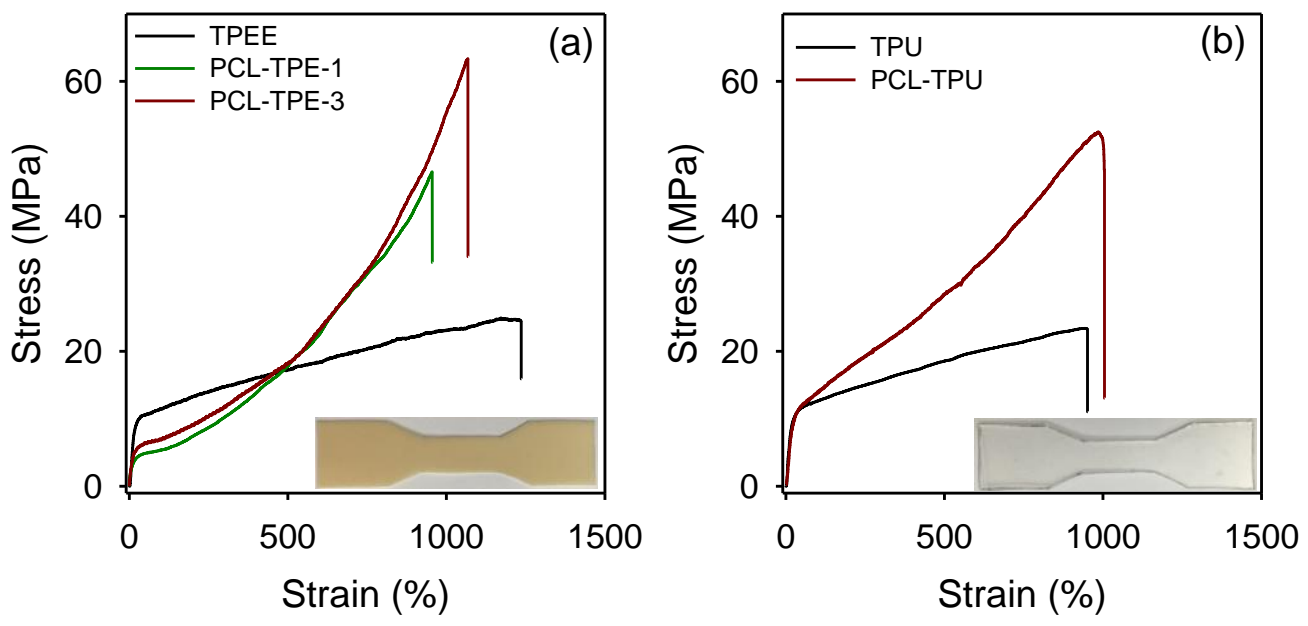

Figure 8. Stress-strain curves for (a) TPEs and (b) TPUs produced by different diols (conducted at a crosshead speed of $100 \mathrm{~mm} \mathrm{~min}^{-1}$ ).

PCL-TPU produced by PG-PCL-1000 also exhibits significantly enhanced mechanical properties compared to that of TPU using PTMEG-1000 (Figure 8b). Accordingly, a tensile strength of $53 \mathrm{MPa}$ with elongation at break of $990 \%$ was obtained for PCL-TPU. The stronger hydrogen-bonds between the $\mathrm{N}-\mathrm{H}$ groups of urethane linkages with $\mathrm{C}=\mathrm{O}$ groups of PCL compared to that of $\mathrm{C}-\mathrm{O}-\mathrm{C}$ groups of PTMEG may account for the mechanical differences.

The rapid growth of the stress at low strain followed by a yielding and a more progressive growth of the stress with the strain (Figure 8) is relevant with a phase separated morphology where the hard segment domains act as reinforcing filler. The higher yield strength for PCL-TPU respect to PCL-TPEs could indicate more phase mixing due to hydrogen-bonds between the $\mathrm{N}-\mathrm{H}$ groups of urethane linkages with $\mathrm{C}=\mathrm{O}$ groups of $\mathrm{PCL}$. The results of the mechanical tests are summarized in Table 6. 
Table 6. Mechanical properties of the resultant TPEs and TPUs ${ }^{1}$.

\begin{tabular}{ccccc}
\hline Samples & $\begin{array}{c}\text { Soft } \\
\text { Segment }\end{array}$ & $\begin{array}{c}\text { Yield Strength } \\
{[\mathbf{M P a}]}\end{array}$ & $\begin{array}{c}\text { Tensile Strength } \\
{[\mathrm{MPa}]}\end{array}$ & $\begin{array}{c}\text { Elongation } \\
{[\%]}\end{array}$ \\
TPEE & PTMEG-1000 & $11 \pm 0.5$ & $25 \pm 2$ & $1230 \pm 38$ \\
PCL-TPE-1 & EG-PCL-1000 & $5 \pm 0.6$ & $47 \pm 3$ & $950 \pm 22$ \\
PCL-TPE-2 & PG-PCL-500 & $7 \pm 0.1$ & $56 \pm 6$ & $1010 \pm 62$ \\
PCL-TPE-3 & PG-PCL-1000 & $6 \pm 0.4$ & $64 \pm 4$ & $1060 \pm 57$ \\
PCL-TPE-4 & PG-PCL-2000 & $8 \pm 0.4$ & $67 \pm 7$ & $1140 \pm 33$ \\
PCL-TPE-5 & PG-PCL-3000 & $8 \pm 0.3$ & $24 \pm 4$ & $1230 \pm 44$ \\
TPU & PTMEG-1000 & $11 \pm 0.6$ & $53 \pm 5$ & $950 \pm 26$ \\
PCL-TPU & PG-PCL-1000 & $12 \pm 0.5$ & $990 \pm 31$ \\
\hline
\end{tabular}

${ }^{1}$ Obtained from the stress-strain curves in Figure 8 and Figure S53, Supporting Information.

\section{Materials and Methods}

\subsection{Materials}

Potassium hexacyanocobaltate(III) $\left(\mathrm{K}_{3}\left[\mathrm{Co}(\mathrm{CN})_{6}\right] ; \geq 97 \%\right)$, anhydrous tert-butyl alcohol (TBA; $\geq 99.5 \%$ ), ethyl acetoacetate (EAA; 99\%), isobutyronitrile (IBN; 99\%), Pluronic P-123 (molecular weight $(\mathrm{MW})=5800)$, polypropylene glycol $(\mathrm{MW}=400)$, ethylene glycol $(\mathrm{EG}$; $\geq 99 \%$ ), propylene glycol (PG; $\geq 99.5 \%$ ), glycerol (GL; $\geq 99 \%$ ), 1-butyl-3-methylimidazolium chloride (BMIMCl; $\geq 98 \%$ ), tetramethylammonium bromide (TMAB; $98 \%$ ), tetraethylammonium bromide (TEAB; 98\%), tetradecyltrimethylammonium bromide (TDAB; $\geq 99 \%$ ), titanium (IV) butoxide (TBT; 97\%), pentaerythritol tetrakis(3,5-di-tert-butyl-4-hydroxyhydrocinnamate) (Irganox 1010, 98\%), and hexamethylene diisocyanate (HDI; $\geq 98 \%$ ) all purchased from SigmaAldrich and used as received. Anhydrous zinc chloride (>98\%), and $\varepsilon$-caprolactone (CL; 99\%) obtained from Alfa Aesar, dibutyltin dilaurate (DBD; >95\%) obtained from TCI and used as received. Glycidol (96\%) obtained from Sigma-Aldrich was dried over calcium hydride and distilled in vacuum directly prior to use. Polymerization grades of dimethyl-2,6-naphthalene dicarboxylate (NDC), PTMEG $(F=2, \mathrm{MW}=1000)$, and 1,4-butanediol (BD) were donated by the Kolon Plastics Co. (Gumi, Republic of Korea) and used after drying. Reagent grades of hexane, chloroform, diethyl ether, ethanol, and dimethylformamide (DMF) were purchased from Dae Jung Chemical Co. (Gyeonggi-do, Korea) and were distilled prior to use.

\subsection{Preparation of DMC Catalyst}

The DMC catalysts used in this work were prepared using TBA, EAA, and IBN as complexing agents following the procedure reported recently [52]. Typically, a mixture of $\mathrm{ZnCl}_{2}(1.23 \mathrm{~g}, 9 \mathrm{mmol})$ and EAA $(0.3 \mathrm{~mL}, 2.4 \mathrm{mmol})$ in aqueous solution was reacted with an aqueous solution of $\mathrm{K}_{3} \mathrm{Co}(\mathrm{CN})_{6}(0.5 \mathrm{~g}, 1.5 \mathrm{mmol})$ for $30 \mathrm{~min}$ at $90{ }^{\circ} \mathrm{C}$. Then, a mixture of EAA ( $1 \mathrm{~mL}, 7.9 \mathrm{mmol})$ and P123 $(0.1 \mathrm{~g}, 0.017 \mathrm{mmol})$ was added and stirred for $10 \mathrm{~min}$. The resulting suspension was separated from the solution by centrifugation $(3000 \times g$ for $10 \mathrm{~min})$, followed by treatment using water $(2.5 \mathrm{~mL}) / \mathrm{EAA}(0.3 \mathrm{~mL}, 2.4 \mathrm{mmol})$ mixture and using EAA $(0.3 \mathrm{~mL}, 2.4 \mathrm{mmol}) / \mathrm{P} 123(0.1 \mathrm{~g}, 0.017 \mathrm{mmol})$ mixture in order. The catalyst slurry separated by centrifugation was washed with $10 \mathrm{~mL}$ of distilled water to remove unreacted $\mathrm{ZnCl}_{2}$. The final wet catalyst cake isolated by centrifugation was dried at $85^{\circ} \mathrm{C}$ under vacuum for $6 \mathrm{~h}$ to a constant weight. This catalyst is identified as DMC-EAA. Similarly, DMC-TBA and DMC-IBN were prepared using TBA and IBN as complexing agents, respectively.

\subsection{Polymerization of $C L$}

All polymerizations were performed using standard Schlenk techniques. In a typical procedure, the prescribed amounts of the DMC catalyst and PG initiator were added to a $10-\mathrm{mL}$ round-bottom flask immersed in an oil bath, purged several times with pure nitrogen at $90{ }^{\circ} \mathrm{C}$ to remove traces of water, and then subjected to various reaction conditions. The products were dissolved in chloroform, centrifuged, and the filtrate was precipitated in diethyl ether. The product suspension was then filtered and dried in a vacuum oven to 
obtain PG-PCL diol. Likewise, EG-PCL, GL-PCL, and SB-PCL polyols were prepared using EG, GL, and SB as initiators, respectively.

For the kinetic study of CL polymerization, a small amount of the reaction mixture was sampled for ${ }^{1} \mathrm{H}$ NMR and GPC analysis during the polymerization.

\subsection{Recycling Experiments}

The polymerization of $\mathrm{CL}$ using EG initiator was conducted using identical procedure as described above. After completion of each cycle, the reaction mixture was cooled to room temperature, dissolved in chloroform, and then centrifuged. The catalyst slurry was then washed thoroughly with chloroform and dried in a vacuum oven prior to reuse in the next cycles.

\subsection{Synthesis of PCL-TPE and PCL-TPU}

The preparation of PCL-TPE was performed in a $250 \mathrm{~mL}$ stainless steel autoclave (Series 4570, Parr Instrument Co, Moline, IL, USA) reactor system equipped with a vacuum pump and Dean Stark apparatus to collect by-products. The reactor was charged with NDC (20.0 g, $81.9 \mathrm{mmol})$, BD (11.1 g, $123.2 \mathrm{mmol})$, and Irganox 1010 (0.2 g, $0.2 \mathrm{mmol})$ and TBT $(0.5 \mathrm{~g}, 1.5 \mathrm{mmol})$. The transesterification reaction was carried out under a nitrogen atmosphere at $160-210{ }^{\circ} \mathrm{C}$ for $90 \mathrm{~min}$, followed by the removal of methanol by-product. After that, prescribed amount of hydroxyl-functionalized PCL or PTMEG was added to the reactor and the polycondensation was conducted under dynamic vacuum $(<25 \mathrm{~Pa})$ at $240{ }^{\circ} \mathrm{C}$ for $1-2 \mathrm{~h}$, depending on the type of polyol. The resulting PCL-TPEs were dissolved in chloroform and precipitated from excess diethyl ether. The precipitate was washed with ethanol and dried at $60^{\circ} \mathrm{C}$ to a constant weight.

The preparation of PCL-TPU was performed in a 3-necked round-bottom flask equipped with a mechanical stirrer and a stopcock-equipped septum inlet for $\mathrm{N}_{2}$ flow control. Prescribed amount of PCL diol or PTMEG was added to the reactor and evacuated for $2 \mathrm{~h}$ at $60^{\circ} \mathrm{C}$. HDI $(3.4 \mathrm{~g}, 20.2 \mathrm{mmol})$ was then added and allowed to react for $3 \mathrm{~h}$. BD $(0.9 \mathrm{~g}$, $10.0 \mathrm{mmol})$ and DBD $(5 \mathrm{mg})$ were added into the mixture and the reactor temperature was raised to $100{ }^{\circ} \mathrm{C}$ and held for an additional $2 \mathrm{~h}$. The time-period of $2 \mathrm{~h}$ was sufficient for complete conversion of hydroxyl groups, as found by titration of -NCO groups with dibutylamine.

\subsection{Characterization}

The ${ }^{1} \mathrm{H}$ NMR and ${ }^{13} \mathrm{C}$ NMR spectra were obtained using a Varian INOVA $400 \mathrm{NMR}$ spectrometer and referenced to the residual solvent signal of $\mathrm{CDCl}_{3}(7.25$ and $77.16 \mathrm{ppm}$, respectively). Gel permeation chromatography (GPC) was performed on a Waters 150 instrument, operating at a flow rate of $1 \mathrm{~mL} \mathrm{~min}^{-1}$ at $40^{\circ} \mathrm{C}$ with 104,103 , and $500 \AA$ columns in tetrahydrofuran, using polystyrene standards. Matrix-assisted laser desorption ionization time-of-flight mass spectrometry (MALDI-TOF-MS) was conducted using a Voyager-DETM STR Biospectrometry Workstation (Applied Biosystems Inc.) equipped with a nitrogen laser delivering $3 \mathrm{~ns}$ laser pulses at $337 \mathrm{~nm}$. Dithranol was used as the matrix. FTIR spectra were collected from 4000 to $400 \mathrm{~cm}^{-1}$ using a Shimadzu IR Prestige 21 spectrometer. X-Ray photoelectron spectroscopy (XPS) analyses were recorded using an ESCALAB 250 induced electron emission spectrometer with monochromatic $\mathrm{Al} \mathrm{K} \alpha$ radiation $(\mathrm{h} v=1486.6 \mathrm{eV}$ ) from an X-ray source operating at $12 \mathrm{~mA}$ and $20 \mathrm{kV}$ (Thermo Fisher Scientific). Elemental analysis of the metals was performed using an inductively coupled plasma optical emission spectrometer (Varian ICP720-OES) equipped with a double-pass glass cyclonic spray chamber, a Sea Spray concentric glass nebulizer and a high solids torch. The samples were digested using aqua regia. Elemental analysis $(\mathrm{C}, \mathrm{H}$, and $\mathrm{N})$ was conducted with a CHNS/O analyzer (Vario-Micro Cube, Elementar Analysensysteme GmbH, Langenselbold, Germany). X-ray powder diffraction (XRD) analysis was performed using a Rigaku RINT2000 wide angle goniometer 185 with $\mathrm{Cu} \mathrm{K} \alpha$ radiation. Thermogravimetric analysis (TGA) and differential scanning calorimetry (DSC) were performed from $20^{\circ} \mathrm{C}$ 
to $800{ }^{\circ} \mathrm{C}$ at a heating rate of $10{ }^{\circ} \mathrm{C} \mathrm{min}-1$ using a TGA Q50 analyzer (TA Instruments, New Castle, DE, USA). The tensile properties of the PCL-TPE and PCL-TPU samples were investigated using a KSU05 machine (Kyungsung Testing Machine Co., Gyeonggi-do, Korea) at room temperature. For the preparation of test specimens, PCL-TPE or PCL-TPU dissolved in chloroform or DMF (3 $\mathrm{wt} \%)$ were poured into a flat mold and subjected to evaporate the solvent at room temperature for 3 days to get films $(\approx 0.3 \mathrm{~mm}$ thickness). The films were then dried at $60-75{ }^{\circ} \mathrm{C}$ under a vacuum oven for $8 \mathrm{~h}$. At least 5 dumbbellshaped specimens ( $50 \mathrm{~mm}$ long $\times 10 \mathrm{~mm}$ width $\times 0.3 \mathrm{~mm}$ thick) were tested at a constant crosshead speed of $100 \mathrm{~mm} \mathrm{~min}^{-1}$ for each sample. The yield strength, tensile strength, and elongation at break were measured from the stress-strain curves of the samples.

\section{Conclusions}

A series of PCLs were synthesized via one-pot, solvent-free ROP of CL, using different DMC catalysts with various initiators. In the presence of the PPG400 initiator, PCL with $M_{n}=1110 \mathrm{~g} \mathrm{~mol}^{-1}, Ð=1.61$, and a monomer conversion of $85 \%$ were obtained after $24 \mathrm{~h}$ at $120^{\circ} \mathrm{C}$. The polymerization of CL initiated by EG, PG, and GL initiators led to higher monomer conversion and produced PCLs with a narrower $Ð$ than those initiated by PPG400. The polymerization of CL exhibited higher efficacy when increased the reaction temperatures. Accordingly, PCLs with $M_{n}$ and $Đ$ values of $950-10,100 \mathrm{~g} \mathrm{~mol}^{-1}$ and 1.10-1.87, respectively, with various architectures ranging from linear to branched were achieved at $160{ }^{\circ} \mathrm{C}$. The PCLs produced in the presence of ILs showed narrower polydispersity than those obtained without using Ils, however, the monomer conversion was significantly reduced and the MW. Among DMC catalysts, the DMC-IBN exhibited the highest performance with over $90 \%$ of monomer conversion within $3 \mathrm{~h}$ at $160{ }^{\circ} \mathrm{C}$. Recyclability of the catalyst was demonstrated without the need for any additional treatment and with no significant loss in efficiency with repeated use.

Kinetic studies demonstrated that the DMC-catalyzed ROP of CL proceeded via a similar mechanism with the coordination polymerization, with typical characteristics of a living polymerization. The reaction was initiated by the nucleophilic attack of the hydroxyl groups in the initiator onto the carbonyl groups of the coordinated CL monomers at the Zn sites to generate the hydroxy-terminated propagating species, followed by continued insertion of the incoming monomer until almost all the monomers were consumed.

The $\alpha, \omega$-hydroxyl-functionalized PCLs produced poly(ester-ester) and poly(esterurethane) elastomers with excellent mechanical properties. PCL-TPEs exhibit the tensile strength of $47-67 \mathrm{MPa}$ and elongation of 1010-1230\%, which is much better tensile strength than conventional poly(ether-ester) produced using PTMEG (25 MPa/1230\%). The PCLTPU was also exhibited enhanced stress and strain (53 MPa/990\%) compared to the conventional poly(ether-urethane) elastomer $(24 \mathrm{MPa} / 950 \%)$. This work offers a promising approach for synthesizing polyester polyols using easily available heterogeneous catalysts and expanding the scope of DMC catalysis. The polyester polyols produced in this study are effective precursors for the preparation of thermoplastic elastomers with enhanced properties, expanding a wide variety of applications needing high-end processing-performance balance with greater recyclability.

Supplementary Materials: The following are available online at https:/ /www.mdpi.com/article/10 .3390 / catal11091033/s1, FTIR and XPS spectra, XRD patterns, and TGA curves of the DMC catalysts, ${ }^{1} \mathrm{H}-\mathrm{NMR}$ and MALDI-TOF spectra, and GPC curves of PCLs, ${ }^{1} \mathrm{H}-\mathrm{NMR}$ and FT-IR spectra, TGA and DSC curves of TPEs and TPUs, supplementary figures, schemes, and tables.

Author Contributions: C.-H.T.: Data curation, visualization, writing-original draft. M.-W.L.: data curation, writing - review and editing. S.-W.P.: data curation, writing-review and editing. J.-E.J.: data curation, writing-review and editing. S.-J.L.: data curation, writing-review and editing. W.S.: data curation, writing — review and editing. P.H.: funding acquisition, writing-review and editing. I.K.: conceptualization, methodology, funding acquisition, supervision, writing-review and editing. All authors have read and agreed to the published version of the manuscript. 
Funding: This work was supported by the National Research Foundation of Korea (NRF) grant funded by the Korean government (MSIT) (2021R1A2C2003685) and partly supported by Korea Institute of Energy Technology Evaluation and Planning (KETEP) grant funded by the Korea government (MOTIE) (20208401010080). PH also thanks the National Research Foundation of Korea grant funded by the Korea Ministry of Science and ICT (NRF-2016R1D1A1B03933778) for the partial financial support.

Conflicts of Interest: The authors declare no conflict of interest. The funders had no role in the design of the study; in the collection, analyses, or interpretation of data; in the writing of the manuscript, or in the decision to publish the results.

\section{References}

1. Legge, N.R. Thermoplastic Elastomers. Rubber Chem. Technol. 1987, 60, 83-117. [CrossRef]

2. Holden, G. Thermoplastic Elastomers. In Rubber Technology; Morton, M., Ed.; Springer: Boston, MA, USA, 1987 ; pp. 465-481.

3. Yoda, R. Elastomers for biomedical applications. J. Biomater. Sci. Polym. Ed. 1998, 9, 561-626. [CrossRef]

4. Guan, J.; Sacks, M.S.; Beckman, E.J.; Wagner, W.R. Synthesis, characterization, and cytocompatibility of elastomeric, biodegradable poly(ester-urethane)ureas based on poly(caprolactone) and putrescine. J. Biomed. Mater. Res. 2002, 61, 493-503. [CrossRef]

5. Tang, D.; Macosko, C.W.; Hillmyer, M.A. Thermoplastic polyurethane elastomers from bio-based poly( $\delta$-decalactone) diols. Polym. Chem. 2014, 5, 3231-3237. [CrossRef]

6. Labet, M.; Thielemans, W. Synthesis of polycaprolactone: A review. Chem. Soc. Rev. 2009, 38, 3484-3504. [CrossRef]

7. Gustini, L.; Lavilla, C.; Finzel, L.; Noordover, B.A.J.; Hendrix, M.M.R.M.; Koning, C.E. Sustainable Coatings from Bio-Based, Enzymatically Synthesized Polyesters with Enhanced Functionalities. Polym. Chem. 2016, 7, 6586-6597. [CrossRef]

8. Brannigan, R.P.; Walder, A.; Dove, A.P. Application of functional diols derived from pentaerythritol as chain extenders in the synthesis of novel thermoplastic polyester-urethane elastomers. Polym. Chem. 2019, 10, 5236-5241. [CrossRef]

9. Shen, Y.; Shen, Z.; Shen, J.; Zhang, Y.; Yao, K. Characteristics and Mechanism of $\varepsilon$-Caprolactone Polymerization with Rare Earth Halide Systems. Macromolecules 1996, 29, 3441-3446. [CrossRef]

10. Albertsson, A.-C.; Varma, I.K. Recent Developments in Ring Opening Polymerization of Lactones for Biomedical Applications. Biomacromolecules 2003, 4, 1466-1486. [CrossRef] [PubMed]

11. Baheti, P.; Gimello, O.; Bouilhac, C.; Lacroix-Desmazes, P.; Howdle, S.M. Sustainable Synthesis and Precise Characterisation of Bio-Based Star Polycaprolactone Synthesised with a Metal Catalyst and with Lipase. Polym. Chem. 2018, 9, 5594-5607. [CrossRef]

12. Lee, K.W.; Chung, J.W.; Kwak, S.-Y. Highly Branched Polycaprolactone/Glycidol Copolymeric Green Plasticizer by One-Pot Solvent-Free Polymerization. ACS Sustain. Chem. Eng. 2018, 6, 9006-9017. [CrossRef]

13. Guarino, V.; Gentile, G.; Sorrentino, L.; Ambrosio, L. Polycaprolactone: Synthesis, Properties, and Applications. In Encyclopedia of Polymer Science and Technology; Matyjaszewski, K., Ed.; John Wiley \& Sons: New York, NY, USA, 2017; pp. 1-36.

14. Kamaruzaman, M.R.; Chin, S.Y.; Pui, E.C.L.; Prasetiawan, H.; Azizan, N. Synthesis of Biobased Polyester Polyol through Esterification of Sorbitol with Azelaic Acid Catalyzed by Tin(II) Oxide: A Kinetic Modeling Study. Ind. Eng. Chem. Res. 2019, 58, 510-516. [CrossRef]

15. Ito, K.; Hashizuka, Y.; Yamashita, Y. Equilibrium Cyclic Oligomer Formation in the Anionic Polymerization of $\varepsilon$-Caprolactone. Macromolecules 1977, 10, 821-824. [CrossRef]

16. Penczek, S. Cationic Ring-Opening Polymerization (CROP) Major Mechanistic Phenomena. J. Polym. Sci. A Polym. Chem. 2000, 38, 1919-1933. [CrossRef]

17. Bourissou, D.; Martin-Vaca, B.; Dumitrescu, A.; Graullier, M.; Lacombe, F. Controlled Cationic Polymerization of Lactide. Macromolecules 2005, 38, 9993-9998. [CrossRef]

18. Hong, M.; Chen, J.; Chen, E.Y.X. Polymerization of Polar Monomers Mediated by Main-Group Lewis Acid-Base Pairs. Chem. Rev. 2018, 118, 10551-10616. [CrossRef]

19. Dale, J.; Schwartz, J.-E. Macrocyclic oligolactones by oligomerization of simple lactones. Acta Chem. Scand. 1986, B40, 559-567. [CrossRef]

20. Shen, Z.; Chen, X.; Shen, Y.; Zhang, Y. Ring-Opening polymerization of $\varepsilon$-caprolactone by rare earth coordination catalysts. I. Characteristics, kinetics, and mechanism of $\varepsilon$-caprolactone polymerization with nd(acac) $)_{3} \cdot 3 \mathrm{H}_{2} \mathrm{O}_{-} \mathrm{ALET}_{3}$ system. J. Polym. Sci. A Polym. Chem. 1994, 32, 597-603. [CrossRef]

21. Kuran, W. Coordination polymerization of heterocyclic and heterounsaturated monomers. Prog. Polym. Sci. 1998, 23, 919-992. [CrossRef]

22. Kowalski, A.; Duda, A.; Penczek, S. Kinetics and Mechanism of Cyclic Esters Polymerization Initiated with Tin(Ii) Octoate, 1. Polymerization of $\varepsilon$-Caprolactone. Macromol. Rapid Commun. 1998, 19, 567-572.

23. Oshimura, M.; Takasu, A. Controlled Ring-Opening Polymerization of $\varepsilon$-Caprolactone Catalyzed by Rare-Earth Perfluoroalkanesulfonates and Perfluoroalkanesulfonimides. Macromolecules 2010, 43, 2283-2290. [CrossRef]

24. Baśko, M.; Kubisa, P. Mechanism of Propagation in the Cationic Polymerization of L,L-Lactide. J. Polym. Sci. A Polym. Chem. 2008, 46, 7919-7923. [CrossRef] 
25. Makiguchi, K.; Satoh, T.; Kakuchi, T. Diphenyl Phosphate as an Efficient Cationic Organocatalyst for Controlled/Living RingOpening Polymerization of $\delta$-Valerolactone and $\varepsilon$-Caprolactone. Macromolecules 2011, 44, 1999-2005. [CrossRef]

26. Saito, T.; Aizawa, Y.; Tajima, K.; Isono, T.; Satoh, T. Organophosphate-catalyzed bulk ring-opening polymerization as an environmentally benign route leading to block copolyesters, end-functionalized polyesters, and polyester-based polyurethane. Polym. Chem. 2015, 6, 4374-4384. [CrossRef]

27. Nederberg, F.; Connor, E.F.; Möller, M.; Glauser, T.; Hedrick, J.L. New Paradigms for Organic Catalysts: The First Organocatalytic Living Polymerization. Angew. Chem. Int. Ed. 2001, 40, 2712-2715. [CrossRef]

28. Lohmeijer, B.G.G.; Pratt, R.C.; Leibfarth, F.; Logan, J.W.; Long, D.A.; Dove, A.P.; Nederberg, F.; Choi, J.; Wade, C.; Waymouth, R.M.; et al. Guanidine and Amidine Organocatalysts for Ring-Opening Polymerization of Cyclic Esters. Macromolecules 2006, 39, 8574-8583. [CrossRef]

29. Martello, M.T.; Burns, A.; Hillmyer, M.A. Bulk Ring-Opening Transesterification Polymerization of the Renewable $\delta$-Decalactone Using an Organocatalyst. ACS Macro Lett. 2012, 1, 131-135. [CrossRef]

30. Kamber, N.E.; Jeong, W.; Waymouth, R.M.; Pratt, R.C.; Lohmeijer, B.G.G.; Hedrick, J.L. Organocatalytic Ring-Opening Polymerization. Chem. Rev. 2007, 107, 5813-5840. [CrossRef] [PubMed]

31. Kiesewetter, M.K.; Shin, E.J.; Hedrick, J.L.; Waymouth, R.M. Organocatalysis: Opportunities and Challenges for Polymer Synthesis. Macromolecules 2010, 43, 2093-2107. [CrossRef]

32. Fukushima, K.; Nozaki, K. Organocatalysis: A Paradigm Shift in the Synthesis of Aliphatic Polyesters and Polycarbonates. Macromolecules 2020, 53, 5018-5022. [CrossRef]

33. Storey, R.F.; Sherman, J.W. Kinetics and Mechanism of the Stannous Octoate-Catalyzed Bulk Polymerization of $\varepsilon$-Caprolactone. Macromolecules 2002, 35, 1504-1512. [CrossRef]

34. Hacker, M.C.; Mikos, A.G. 35-Synthetic Polymers. In Principles of Regenerative Medicine; Atala, A., Lanza, R., Thomson, J.A., Nerem, R.M., Eds.; Academic Press: San Diego, CA, USA, 2008; pp. 604-635.

35. Martin, E.; Dubois, P.; Jérôme, R. Polymerization of $\varepsilon$-Caprolactone Initiated by Y Alkoxide Grafted onto Porous Silica. Macromolecules 2003, 36, 7094-7099. [CrossRef]

36. Wilson, B.C.; Jones, C.W. A Recoverable, Metal-Free Catalyst for the Green Polymerization of $\varepsilon$-Caprolactone. Macromolecules 2004, 37, 9709-9714. [CrossRef]

37. Oshimura, M.; Takasu, A.; Nagata, K. Controlled Ring-Opening Polymerization of $\epsilon$-Caprolactone Using Polymer-Supported Scandium Trifluoromethanesulfonate in Organic Solvent and Ionic Liquids. Macromolecules 2009, 42, 3086-3091. [CrossRef]

38. Choi, S.J.; Choi, E.H.; Song, C.; Ko, Y.-J.; Lee, S.M.; Kim, H.J.; Jang, H.-Y.; Son, S.U. Hyper-Cross-Linked Polymer on the Hollow Conjugated Microporous Polymer Platform: A Heterogeneous Catalytic System for Poly(caprolactone) Synthesis. ACS Macro Lett. 2019, 8, 687-693. [CrossRef]

39. Yu, K.; Jones, C.W. Elucidating the Role of Silica Surfaces in the Ring-Opening Polymerization of Lactide: Catalytic Behavior of Silica-Immobilized Zinc B-Diiminate Complexes. J. Catal. 2004, 222, 558-564. [CrossRef]

40. Long, W.; Gill, C.S.; Choi, S.; Jones, C.W. Recoverable and Recyclable Magnetic Nanoparticle Supported Aluminium Isopropoxide for Ring-Opening Polymerization of $\varepsilon$-Caprolactone. Dalton Trans. 2010, 39, 1470-1472. [CrossRef]

41. Kim, I.; Ahn, J.-T.; Ha, C.S.; Yang, C.S.; Park, I. Polymerization of Propylene Oxide by Using Double Metal Cyanide Catalysts and the Application to Polyurethane Elastomer. Polymer 2003, 44, 3417-3428. [CrossRef]

42. Tran, C.H.; Pham, L.T.T.; Jang, H.B.; Kim, S.A.; Kim, I. Effect of $\alpha-, \beta-, \gamma-$, and $\delta$-Dicarbonyl Complexing Agents on the Double Metal Cyanide-Catalyzed Ring-Opening Polymerization of Propylene Oxide. Catal. Today 2021, 375, 429-440. [CrossRef]

43. Dharman, M.M.; Ahn, J.-Y.; Lee, M.-K.; Shim, H.-L.; Kim, K.-H.; Kim, I.; Park, D.-W. Moderate Route for the Utilization of $\mathrm{CO}_{2}$-Microwave Induced Copolymerization with Cyclohexene Oxide Using Highly Efficient Double Metal Cyanide Complex Catalysts Based on $\mathrm{Zn}_{3}\left[\mathrm{Co}(\mathrm{CN})_{6}\right]$. Green Chem. 2008, 10, 678-684. [CrossRef]

44. Zhang, X.-H.; Wei, R.-J.; Zhang, Y.Y.; Du, B.-Y.; Fan, Z.-Q. Carbon Dioxide/Epoxide Copolymerization via a Nanosized ZincCobalt(III) Double Metal Cyanide Complex: Substituent Effects of Epoxides on Polycarbonate Selectivity, Regioselectivity and Glass Transition Temperatures. Macromolecules 2015, 48, 536-544. [CrossRef]

45. Tran, C.H.; Kim, S.A.; Moon, Y.; Lee, Y.; Ryu, H.M.; Baik, J.H.; Hong, S.C.; Kim, I. Effect of Dicarbonyl Complexing Agents on Double Metal Cyanide Catalysts Toward Copolymerization of $\mathrm{CO}_{2}$ and Propylene Oxide. Catal. Today 2021, 375, 335-342. [CrossRef]

46. Sreeprasanth, P.S.; Srivastava, R.; Srinivas, D.; Ratnasamy, P. Hydrophobic, Solid Acid Catalysts for Production of Biofuels and Lubricants. Appl. Catal. A 2006, 314, 148-159. [CrossRef]

47. Herzberger, J.; Niederer, K.; Pohlit, H.; Seiwert, J.; Worm, M.; Wurm, F.R.; Frey, H. Polymerization of ethylene oxide, propylene oxide, and other alkylene oxides: Synthesis, novel polymer architectures, and bioconjugation. Chem. Rev. 2016, 116, $2170-2243$. [CrossRef] [PubMed]

48. Liu, Z.-H.; Li, Y.; Zhang, C.-J.; Zhang, Y.-Y.; Cao, X.-H.; Zhang, X.-H. Synthesis of high-molecular-weight poly( $\varepsilon$-caprolactone) via heterogeneous zinc-cobalt(III) double metal cyanide complex. Giant 2020, 3, 100030. [CrossRef]

49. Báez, J.E.; Marcos-Fernández, Á.; Lebrón-Aguilar, R.; Martínez-Richa, A. A novel route to $\alpha, \omega$-telechelic poly( $\varepsilon$-caprolactone) diols, precursors of biodegradable polyurethanes, using catalysis by decamolybdate anion. Polymer 2006, 47, 8420-8429. [CrossRef]

50. Stevels, W.M.; Ankoné, M.J.K.; Dijkstra, P.J.; Feijen, J. Kinetics and Mechanism of $\varepsilon$-Caprolactone Polymerization Using Yttrium Alkoxides as Initiators. Macromolecules 1996, 29, 8296-8303. [CrossRef] 
51. Martin, E.; Dubois, P.; Jérôme, R. Controlled Ring-Opening Polymerization of $\varepsilon$-Caprolactone Promoted by "in Situ" Formed Yttrium Alkoxides. Macromolecules 2000, 33, 1530-1535. [CrossRef]

52. Tran, C.H.; Pham, L.T.T.; Lee, Y.; Jang, H.B.; Kim, S.; Kim, I. Mechanistic Insights on Zn(II)-Co(III) Double Metal CyanideCatalyzed Ring-Opening Polymerization of Epoxides. J. Catal. 2019, 372, 86-102. [CrossRef]

53. Tran, C.H.; Lee, M.W.; Kim, S.A.; Jang, H.B.; Kim, I. Kinetic and Mechanistic Study of Heterogeneous Double Metal CyanideCatalyzed Ring-Opening Multibranching Polymerization of Glycidol. Macromolecules 2020, 53, 2051-2060. [CrossRef]

54. Alagi, P.; Ghorpade, R.; Choi, Y.J.; Patil, U.; Kim, I.; Baik, J.H.; Hong, S.C. Carbon dioxide-based polyols as sustainable feedstock of thermoplastic polyurethane for corrosion-resistant metal coating. ACS Sustain. Chem. Eng. 2017, 5, 3871-3881. [CrossRef] 